\title{
On mapping seafloor mineral deposits with central loop transient electromagnetics
}

\author{
Andrei Swidinsky ${ }^{1}$, Sebastian Hölz ${ }^{1}$, and Marion Jegen ${ }^{1}$
}

\begin{abstract}
Electromagnetic methods are commonly employed in exploration for land-based mineral deposits. A suite of airborne, land, and borehole electromagnetic techniques consisting of different coil and dipole configurations have been developed over the last few decades for this purpose. In contrast, although the commercial value of marine mineral deposits has been recognized for decades, the development of suitable marine electromagnetic methods for mineral exploration at sea is still in its infancy. One particularly interesting electromagnetic method, which could be used to image a mineral deposit on the ocean floor, is the central loop configuration. Central loop systems consist of concentric transmitting and receiving loops of wire. While these types of systems are frequently used in land-based or airborne surveys, to our knowledge neither system has been used for marine mineral exploration. The advantages of using
\end{abstract}

central loop systems at sea are twofold: (1) simplified navigation, because the transmitter and receiver are concentric, and (2) simplified operation because only one compact unit must be deployed. We produced layered seafloor type curves for two particular types of central loop methods: the in-loop and coincident loop configurations. In particular, we consider models inspired by real marine mineral exploration scenarios consisting of overburdens 0 to $5 \mathrm{~m}$ thick overlying a conductive ore body 5 to $30 \mathrm{~m}$ thick. Modeling and resolution analyses showed that, using a $50 \mathrm{~m}^{2}$ transmitting loop with $20 \mathrm{~A}$ of current, these two configurations are useful tools to determine the overburden depth to a conductive ore deposit and its thickness. In the most extreme case, absolute voltage errors on the order of $10 \mathrm{nV}$ are required to resolve the base of a $30 \mathrm{~m}$ thick ore deposit. Whether such noise floors can be achieved in real marine environments remains to be seen.

\section{INTRODUCTION}

Marine ore deposits are widespread on the ocean floor; they typically occur in environments such as spreading ridges, as well as around volcanoes and seamounts (Rona, 1984). Of the various types of seafloor deposits, the focus of this paper is concerned with polymetallic sulfides that are associated with hydrothermal venting. Several deposits are large enough to be commercially viable, such as in the Red Sea (Herzig and Hannington, 1995; Bertram et al., 2011) and offshore Papua New Guinea (Lipton, 2008). Increased demand for rare earth materials and generally improved marine technology are currently driving the economic development of these deposits.

Sulfide deposits are generated at active hydrothermal vent sites on midocean ridges, marine volcanic systems and oceanic back- arcs (e.g., Robb, 2005). Currently and recently formed deposits may be located through mapping of hydrothermal circulation, visual inspection, or chemical observation in the water column. Exploration for these deposits in general often involves highresolution seafloor bathymetry focused on characteristic surface expressions of vent sites. Shallow coring or borehole work is sometimes carried out to determine the depth extent and grade of mineralization. Through tectonic processes deposits can be carried away from the active hydrothermal sites. Even though present active distributions can be used to predict the occurrence of now inactive systems off axis, those without any active markers have little or no surface expression and may potentially be masked by sediments or overlying lava flows. However, ore deposits have distinct geophysical properties which allow their remote assessment. Due to the high grade of mineralization, sulfide deposits are characterized

Manuscript received by the Editor 2 July 2011; revised manuscript received 22 November 2011; published online 12 April 2012.

${ }^{1}$ Helmholtz-Zentrum für Ozeanforschung Kiel (GEOMAR), Geodynamics Department, Kiel, Germany. E-mail: aswidinsky@geomar.de; shoelz@ geomar.de; mjegen@geomar.de.

(C) 2012 Society of Exploration Geophysicists. All rights reserved. 
by strong electrical conductivity anomalies. One example of this is shown in experiments at the TAG hydrothermal mounts on the Mid-Atlantic Ridge (Cairns et al., 1996; von Herzen et al., 1996).

In land-based exploration, electromagnetic methods have been a popular technique for determining the quantity and quality of an ore deposit. In the last few decades, a suite of airborne, land, and borehole electromagnetic methods consisting of different coil and dipole configurations have been developed for mineral exploration on land (Grant and West, 1965; Palacky and West, 1991). However, although the commercial value of marine ore deposits has been known for decades, the development of suitable electromagnetic methods for marine mineral exploration is still in its infancy.

There is a large amount of literature available for electrical studies of the seafloor (Chave and Cox, 1982; Edwards et al., 1985; Edwards and Chave, 1986). Early works contained some aspects concerning the detection of conductive targets (e.g., Chave et al., 1991), which are of general interest for deep sea mining. Among the studies available, Coggon and Morrison (1970) produced type curves of a two layered conductive seafloor for a frequency domain marine controlled-source electromagnetic (CSEM) system consisting of a magnetic dipole source and receiver. Chave et al. (1991) summarized resistivity surveys used to map various targets including conductive seafloor sulfide zones (such as Francis, 1985), while Kaufman and Keller (1983) and Cheesman et al. (1987) examined the response of various CSEM systems commonly used on land to determine their applicability in marine environments. Similar studies of electromagnetic methods for conductive seafloors were also performed by L. L. Vanyan and others in the former Soviet Union (references in Russian). However, within the last decade, the focus of marine electromagnetics has concentrated on the detection of resistive targets, mainly for hydrocarbon exploration (Edwards, 1997; Ellingsrud et al., 2002).

A particularly interesting CSEM system considered by Cheesman et al. (1987) is the central loop configuration. Central loop systems consist of a concentric transmitting loop of wire and a receiving coil; an electrical current in the transmitting loop is used to generate a primary magnetic field. After the current is switched off, current flow is induced in the conductive medium. A system which measures the corresponding induced voltage in a small coil at the center of a loop source is commonly referred to as an in-loop configuration. Alternatively, a system in which induced voltage is measured by a receiving coil located coincident to the transmitting

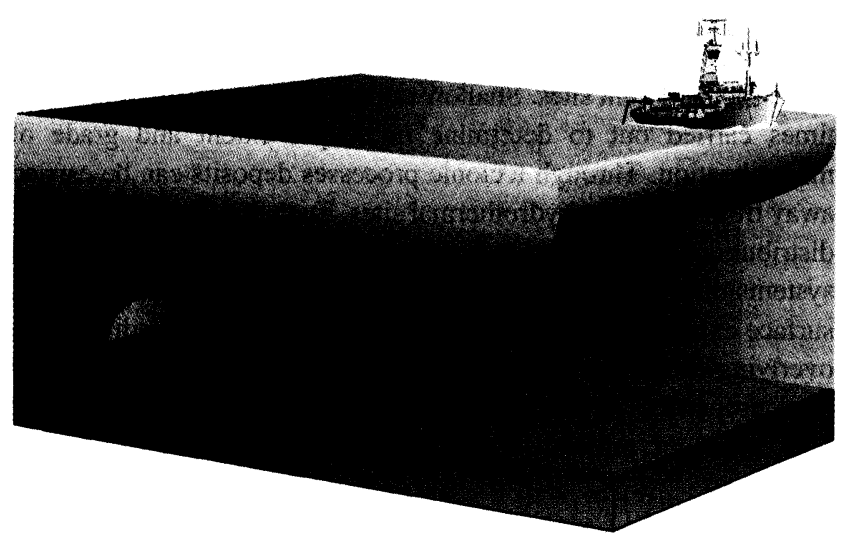

Figure 1. The experimental configuration of the seafloor transient coincident loop system. loop is commonly referred to as a coincident loop configuration. In a 1D earth, these types of configurations produce only a transverse electric (TE) mode of field propagation. This mode only consists of horizontal current flow in the earth and lacks a vertical electric field. Resistive structures distort vertical current flow; as a result, all configurations with a vertical magnetic dipole source, such as central loop systems, are insensitive to such targets (except in the case of mode conversions). On the other hand, they should be very sensitive to conductive structures as the horizontal current systems they produce are inductive and are similar to those used in the magnetotelluric (MT) method (note that this is likewise the case for horizontal electric and magnetic dipoles, which also produce a TE mode). However, the natural sources used in marine MT are typically low frequency due to the overlying conductive seawater, leading to a very low spatial resolution on the order of several hundred meters or more. Using an artificial loop source on the seafloor allows for the generation of short wavelength and high-frequency components of the electromagnetic field. This has the effect of increasing spatial resolution to the scale required for near seafloor mineral exploration. The advantages of central loop systems in the marine environment are twofold: (1) simplified navigation, because the transmitter and receiver are concentric and (2) simplified operation, because only one compact unit must be deployed. Figure 1 shows an illustration of a marine coincident loop sounding. While such systems are used extensively in land-based (Danielsen et al., 2003; Hölz et al., 2007), airborne investigations (Sørensen and Auken, 2004), and even on the ocean surface for bathymetric studies (Vrbancich et al., 2010), their application on the ocean floor has rarely been discussed. Cheesman et al. (1987) and Liu and Lin (2006) calculated, respectively, the in-loop 'and coincident loop response of a double half-space model consisting of seawater overlying a seafloor feature which is more conductive than the oceanic crust. Müller et al. (2012), use a frequency domain concentric loop system modified from a land sensor to map the magnetic susceptibility and electrical conductivity of marine surficial sediments. To our knowledge, these are the only studies in the available literature concerning central loop systems on the ocean floor.

It furthermore appears that no study has examined the response of a central loop system to a seafloor containing a conductive layer. However, layered seafloor models are important as it is typically the top and base of the conductive ore deposit that is of interest in exploration work. For example, Figure 2 shows a geological

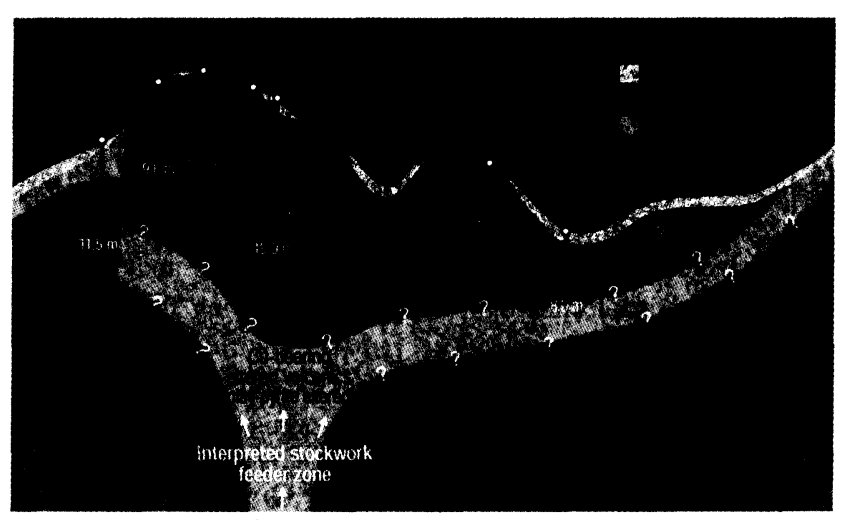

Figure 2. Geological cross section of the Solwara-1 deposit (Lipton, 2008). 
section of a massive sulfide deposit, offshore Papua New Guinea. Here, there is a sedimentary layer overlying a deposit of variable and unknown thickness. Although such mineral deposits are clearly 3D in character, in our case, they may be approximated locally as layered structures because a central loop system is sensitive to a relatively confined volume of seawater and seafloor around the loop position. This is in contrast to regular marine CSEM systems, where transmitter and receiver are usually separated by as much as several thousands of meters. Such configurations sample a much larger volume of seafloor and are consequently more strongly affected by 3D structures. In this paper, we explore the application of central loop transient electromagnetic methods to the mapping of seafloor ore deposits. Specifically, we calculate the electromagnetic fields produced by in-loop and coincident loop systems lying at the surface of a layered seafloor. We consider models inspired by real marine mineral exploration scenarios consisting of overburdens $0 \mathrm{~m}$ to $5 \mathrm{~m}$ thick overlying a conductive sulfide layer $5 \mathrm{~m}$ to $40 \mathrm{~m}$ thick. We also compare the response of central loop systems on land and on the seafloor, similar to Cheesman et al. (1987) in the marine environment the upper half-space has a finite conductivity while on land the upper half-space is a perfect insulator. Finally, we perform a resolution and error analysis of the central loop configurations for these various layered models to determine the resolving ability and the required noise levels of these systems for mineral exploration.

\section{FUNDAMENTAL THEORY}

For the land-case, the theory of a vertical magnetic in-loop or coincident loop system over a 1D layered earth is described in Ward and Hohmann (1987) and summarized in Smith et al. (1994). The extension to a vertical magnetic in-loop system above a layered seafloor, overlain by a homogeneous water column was derived by Chave (2009). We extend these formalisms to include the case of a coincident loop system and generalize it to also include a layered water column. The full, but compact derivation is given in Appendix A. The reader should note that for the penetration depths relevant for a small loop system, in most cases the water column can be considered as a single layer of uniform conductivity at depth. This is because larger contrasts in the conductivity of the water column or the air-water interface are usually out of the range of such systems. However, stable and strongly stratified layering of the water column conductivity near the seafloor has been observed in the vicinity of sulfide deposits (e.g., Hartmann et al., 1998; Schmidt et al., 2003). Therefore, in certain cases, layering of the water column may become a relevant issue in marine sulfide exploration.

Consider a transmitter consisting of a horizontal loop of wire of radius $a$. The loop is situated above a series of $N$ crustal layers including a terminating lower half-space and below a series of $M$ seawater layers including an air upper half-space (see Figure A-1). A current $I$ within the loop is abruptly switched off at a time $t=0$, producing "smoke rings," (Nabighian, 1979) which in the marine case travel downward into the earth and upward into the seawater. The in-loop system measures the voltage $\mathrm{V}$ induced in a small wire loop of radius $b$ located at the center of the transmitting loop. This voltage can be found as the inverse Laplace transform of the expression

$$
V(s)_{\text {in-loop }}=\pi I a b^{2} \int_{0}^{\infty}\left[\frac{P_{1} Q_{1}}{P_{1}+Q_{1}}\right] \lambda^{2} J_{1}(\lambda a) d \lambda,
$$

where $s$ is the Laplace variable, implicitly contained in $P_{1}$ and $Q_{1}$.

Alternatively, the coincident loop system measures the induced voltage in a receiving loop located coincident to the transmitting loop. This voltage can be calculated as the inverse Laplace transform of the expression

$$
V(s)_{\text {coincident loop }}=2 \pi I a^{2} \int_{0}^{\infty}\left[\frac{P_{1} Q_{1}}{P_{1}+Q_{1}}\right] \lambda\left[J_{1}(\lambda a)\right]^{2} d \lambda .
$$

The parameters $P_{1}$ and $Q_{1}$ can be calculated using the upward and downward recursion relationships,

$$
Q_{i}=\frac{\mu_{0}}{\theta_{i}}\left[\frac{\theta_{i} Q_{i+1}+\mu_{0} \tanh \left(\theta_{i} d_{i}\right)}{\mu_{0}+\theta_{i} Q_{i+1} \tanh \left(\theta_{i} d_{i}\right)}\right]
$$

and

$$
P_{j}=\frac{\mu_{0}}{\theta_{j}}\left[\frac{\theta_{j} P_{j+1}+\mu_{0} \tanh \left(\theta_{j} d_{j}\right)}{\mu_{0}+\theta_{j} P_{j+1} \tanh \left(\theta_{j} d_{j}\right)}\right],
$$

where the starting values are $Q_{N}=\mu_{0} / \theta_{N}$ and $P_{M}=\mu_{0} / \theta_{M}$. The wavenumbers $\theta_{i}$ and $\theta_{j}$ are defined as $\theta_{i}^{2}=\lambda^{2}+s \mu_{0} \sigma_{i}$ and $\theta_{j}^{2}=\lambda^{2}+s \mu_{0} \sigma_{j}$ for the $i$ th seafloor and $j$ th seawater layers, respectively and $\theta_{M}^{2}=\lambda^{2}+s^{2} \mu_{0} \varepsilon_{0}$ for the air upper half-space. Although similar in principle, the field expression 1 differs from expression 2 by the nature of the integral kernel. The Hankel transforms in equations 1 and 2 may be calculated using conventional digital filter techniques (Anderson, 1979), while the Laplace transform may be computed using numerical methods such as the Gaver-Stehfest algorithm (Stehfest, 1970; Knight and Raiche, 1982). Alternatively, the Hankel transforms and the inverse Laplace transform may also be evaluated by using appropriate digital filters as described by Johansen and Sørensen (1979), Weidelt (1984), and Christensen (1990).

\section{SEAFLOOR MODEL STUDIES}

Let us apply the theory outlined in the previous section to examine the in-loop and coincident loop response of a conductive seafloor target such as an ore deposit. For our study, let the transmitting loop have a radius of $4 \mathrm{~m}$. This equals a loop area of approximately $50 \mathrm{~m}^{2}$ (at GEOMAR, we currently use a stationary electric dipole source of comparable length dimensions for more conventional marine CSEM applications). All responses will be normalized to the transmitter dipole moment $I \times \pi a^{2}$. In the case of the inloop configuration, we use a receiving loop with an effective loop area of $1 \mathrm{~m}^{2}$; responses for different receiving loop sizes may be scaled accordingly. Consider the models shown in Figure 3. In both cases, the seawater is represented by a half-space with a conductivity of $3 \mathrm{~S} / \mathrm{m}$. In practice, appropriate values should be chosen according to in-situ conductivity-temperature-depth measurements. However, an assumption of uniform seawater conductivity should be sufficient for most practical scenarios because the penetration depth of a loop system is of the order of the loop radius. Regardless, if this is actually the case, the responses can be easily modified by introducing layering in the seawater using equation 4 . This special 
treatment may be necessary in cases where a strongly stratified water column exists close to the seafloor (Hartmann et al., 1998; Schmidt et al., 2003). In Appendix B, we describe a situation where stable layering of the electrical conductivity in the water column near the seafloor has been observed, and further show that this layering can significantly affect the central loop response. However, for our present purposes we will limit our discussions and calculations in the main body of this paper to the simple case of a uniform seawater column. Model A is an illustrative example of a simple uniform seafloor with variable conductivity, like that considered in Cheesman et al. (1987) and Liu and Lin (2006). The seafloor model B consists of two layers overlying a half-space. Such a model is consistent with known near surface seafloor sulfide deposits (see Figure 2). Here, there is a conductive sulfide zone of variable thickness which is buried under an overburden layer of variable depth, and which overlies a relatively more resistive basement. In a typical exploration scenario, the electrical conductivity of the overburden, sulfide deposit and basement are often quite well known through borehole logging. Conversely, the overburden depth and sulfide thickness may be quite variable and their mapping can be very valuable in an interpretation stage.

Figure 4 shows the in-loop response of model $\mathrm{A}$. The seafloor conductivity ranges logarithmically from $1 \mathrm{~S} / \mathrm{m}$ to $100 \mathrm{~S} / \mathrm{m}$, a reasonable estimate of the upper limit of a real sulfide deposit. First of all, note that resistive seafloors $(<1 \mathrm{~S} / \mathrm{m})$ give the same response as a $1 \mathrm{~S} / \mathrm{m}$ seafloor. This shows why the in-loop configuration is not practical for the investigation of resistive targets such as oil, gas and gas hydrate deposits. However, the responses for a conductive seafloor $(1 \mathrm{~S} / \mathrm{m}-100 \mathrm{~S} / \mathrm{m})$ are clearly distinguishable. Observe the fundamental and well known feature of the transient response: the bulk arrival of electromagnetic fields and consequently the decay of the induced voltages are proportional to the seafloor conductivity. Figure 5a shows the in-loop response of model B. The overburden thickness varies linearly from 0 to $5 \mathrm{~m}$. A variety of conductor thicknesses are considered. Also shown on the plot are three source normalized error floors, each inversely proportional to the square root
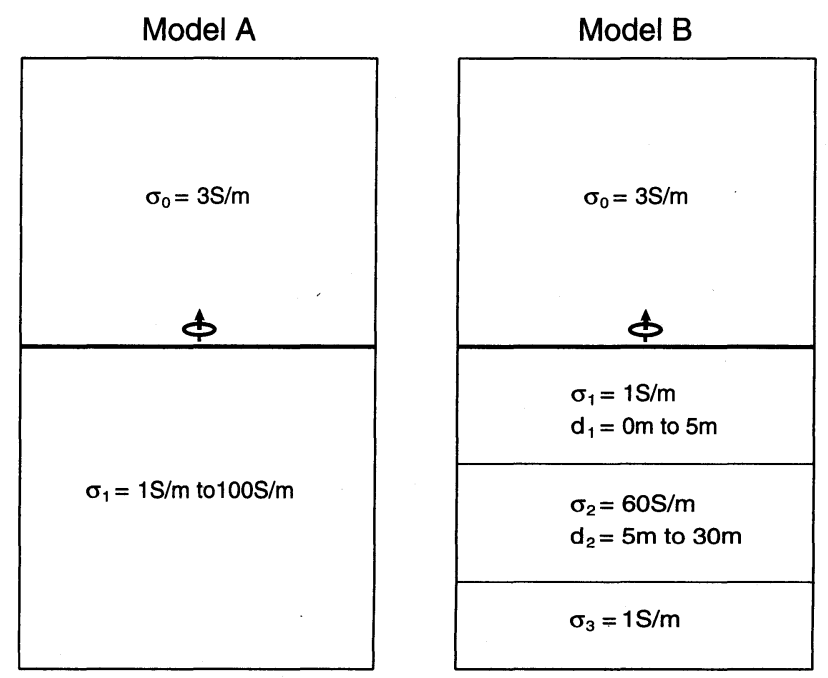

Figure 3. Two simple seafloor models used in this study. Model A: A double half-space. Model B: A seafloor consisting of two layers above a half-space. of the time, approaching $0.1 \mathrm{nV} / \mathrm{A} \times \mathrm{m}^{2}, \quad 1 \mathrm{nV} / \mathrm{A} \times \mathrm{m}^{2}$ and $10 \mathrm{nV} / \mathrm{A} \times \mathrm{m}^{2}$ at $1 \mathrm{~s}$, respectively. This form of noise dependence is common for transient electromagnetic data that are processed and binned in logarithmic time (Munkholm and Auken, 1996). These noise floors should be considered as a rough guide for experimental design - what sort of noise levels can be achieved in practice on the ocean floor remains to be seen. As the noise floors are source normalized, an increase in source dipole moment will increase the signal to noise ratio by reducing these source normalized noise levels. For clarity, Figure $5 b$ shows the response of different overburden thicknesses only for a $5 \mathrm{~m}$ thick conductor, while Figure 5c shows the response of different conductor thicknesses for a $0 \mathrm{~m}$ overburden. Figure $5 \mathrm{~d}, 5 \mathrm{e}$, and $5 \mathrm{f}$ shows the same responses, but normalized to a $1 \mathrm{~S} / \mathrm{m}$ host seafloor half-space - a typical procedure in for a dipole-dipole marine CSEM system. At early times, the responses for different overburden depths are clearly resolved. Moreover, this early time effect is independent of the conductor thickness. Note that although at later times the responses for different conductor thicknesses are also resolvable, for our size of receiving loop they occur at scales of $0.1 \mathrm{nV} / \mathrm{A} \times \mathrm{m}^{2}$ and below. However, it is important to realize that these responses will scale with the moment of the transmitting loop and the size of the receiving loop. We may conclude from these results that the in-loop configuration is a useful tool to determine the overburden depth to a conductor. However, the configuration requires low noise levels to be sensitive to the conductor thickness for the type of model we consider. The required noise level to determine overburden depths and conductor thicknesses is no more than a guide to instrumental design. It may or may not be possible to achieve these levels in practice.

Figure 6 shows the coincident loop response of model A. The seafloor conductivity ranges logarithmically from $1 \mathrm{~S} / \mathrm{m}$ to $100 \mathrm{~S} / \mathrm{m}$ in the same manner as in Figure 3. Similar to the in-loop type curves, this system has no sensitivity to a resistive seafloor. However, for a conductive seafloor the decay of the induced voltage

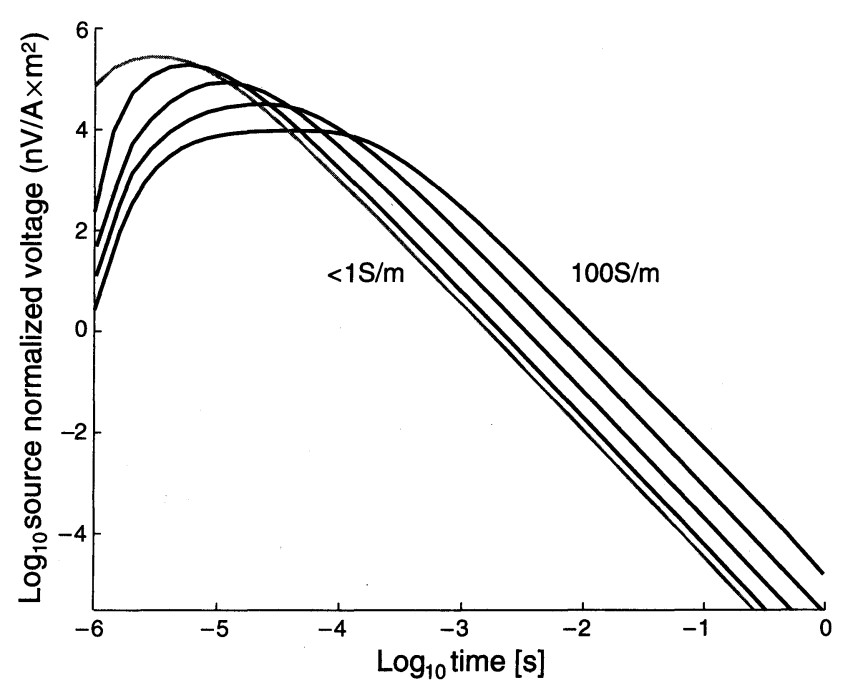

Figure 4. The in-loop response of model A. The seafloor conductivity ranges logarithmically with values of $1 \mathrm{~S} / \mathrm{m}$ (gray), $3 \mathrm{~S} / \mathrm{m}$, $10 \mathrm{~S} / \mathrm{m}, 30 \mathrm{~S} / \mathrm{m}$ and $100 \mathrm{~S} / \mathrm{m}$ (only $1 \mathrm{~S} / \mathrm{m}$ and $100 \mathrm{~S} / \mathrm{m}$ notated). Note that all responses for seafloor conductivities less than $1 \mathrm{~S} / \mathrm{m}$ will be identical to the $1 \mathrm{~S} / \mathrm{m}$ gray curve. 
is again proportional to the seafloor conductivity. Figure 7a shows the coincident loop step response of model B. Similar to the in-loop type curves, the overburden depth varies linearly from 0 to $5 \mathrm{~m}$. A variety of conductor thicknesses are considered. Also shown on the plot are three source normalized error floors, each inversely proportional to the square root of the time, in this case approaching $1 \mathrm{nV} / \mathrm{A} \times \mathrm{m}^{2}, 10 \mathrm{nV} / \mathrm{A} \times \mathrm{m}^{2}$ and $100 \mathrm{nV} / \mathrm{A} \times \mathrm{m}^{2}$ at $1 \mathrm{~s}$, respectively. Again for clarity, Figure $7 \mathrm{~b}$ shows the response of different overburden thicknesses only for a $5 \mathrm{~m}$ thick conductor, while Figure $7 \mathrm{c}$ shows the response of different conductor thicknesses
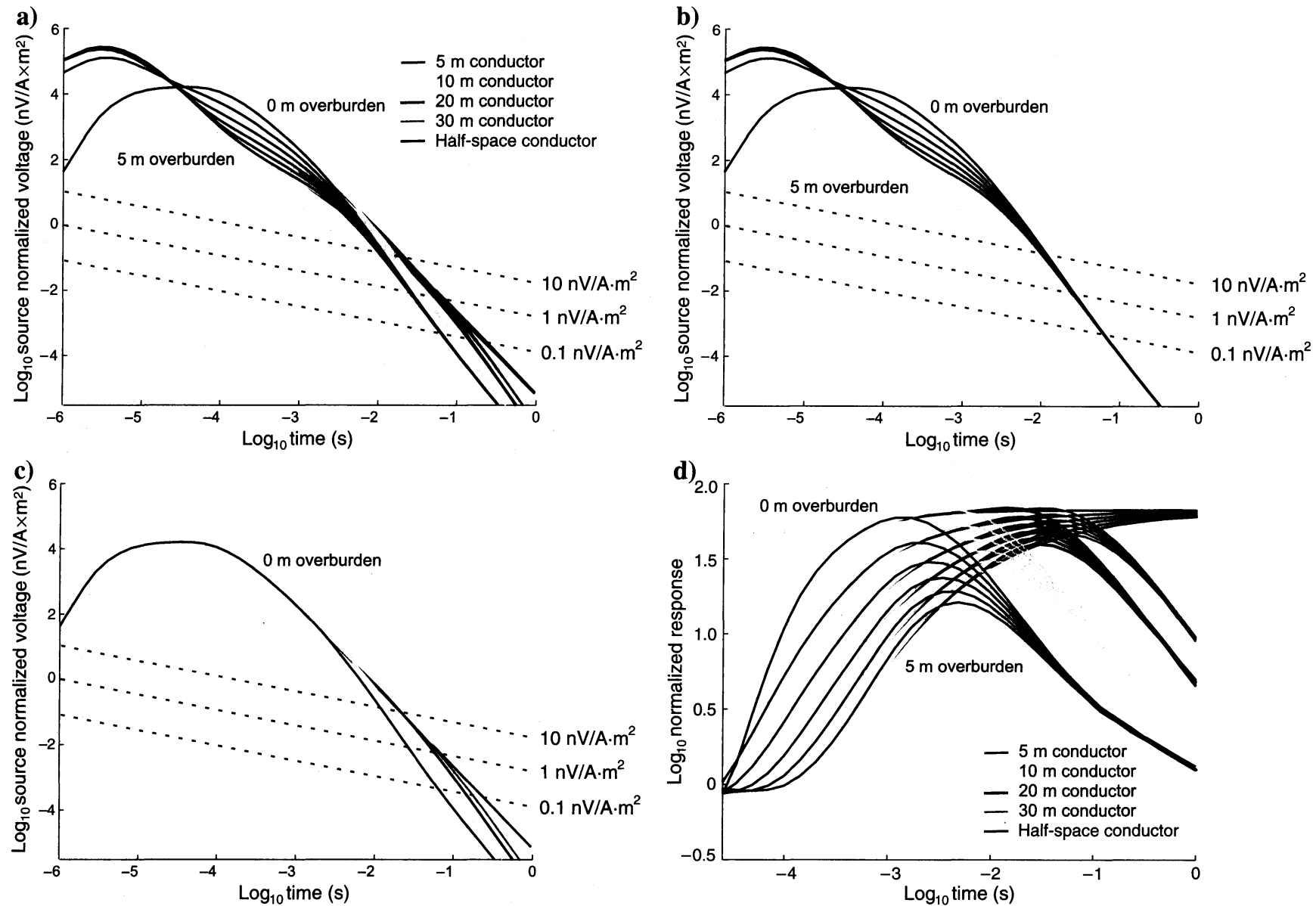

()
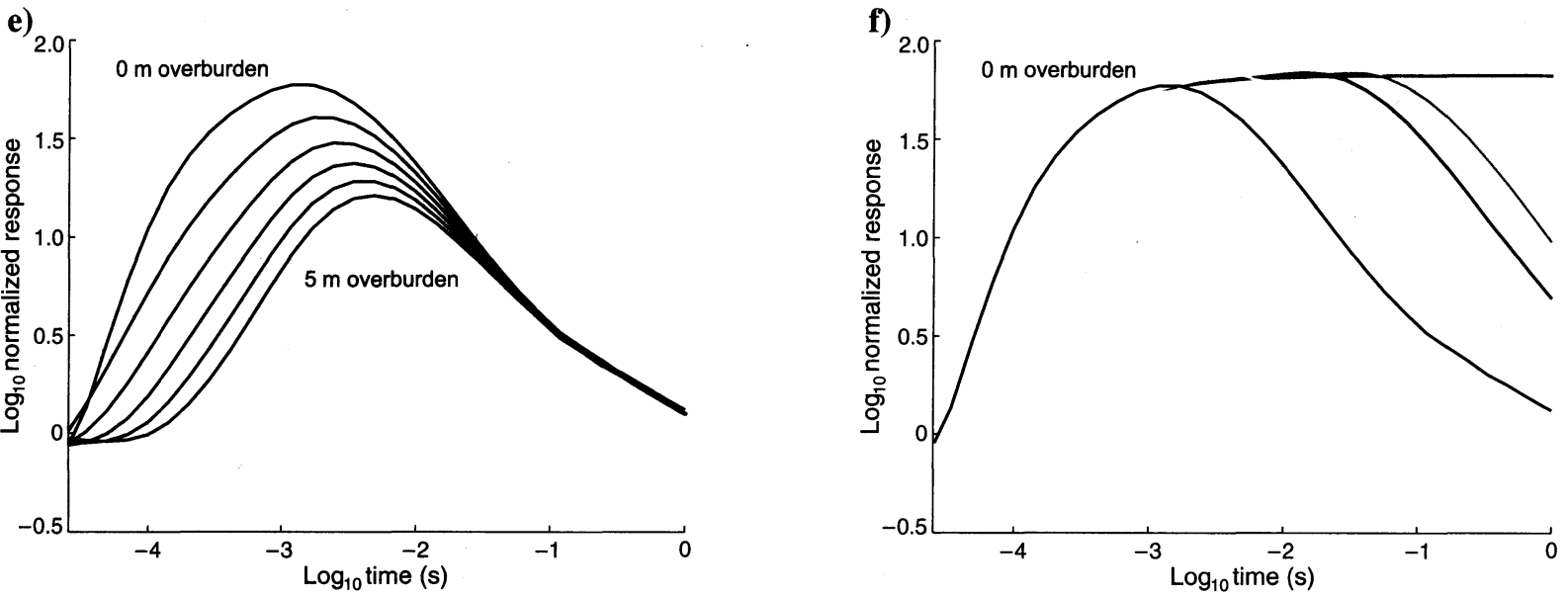

Figure 5. The in-loop response of model B for different conductor thicknesses. The overburden depth ranges linearly from $0 \mathrm{~m}$ to $5 \mathrm{~m}$. (a) True response. (b) True response, showing only type curves of the $5 \mathrm{~m}$ conductor for varying overburden thickness. (c) True response, showing only type curves of the $0 \mathrm{~m}$ overburden model for varying conductor thicknesses. (d) True response normalized by a $1 \mathrm{~S} / \mathrm{m}$ seafloor half-space. (e) Normalized response of the $5 \mathrm{~m}$ conductor. (f) Normalized response of the $0 \mathrm{~m}$ overburden model. Also shown on (a), (b), and (c) are three source normalized error floors, each inversely proportional to the square root of the time, approaching $0.1 \mathrm{nV} / \mathrm{A} \times \mathrm{m}^{2}, 1 \mathrm{nV} / \mathrm{A} \times \mathrm{m}^{2}$ and $10 \mathrm{nV} / \mathrm{A} \times \mathrm{m}^{2}$ at $1 \mathrm{~s}$, respectively. 
for a $0 \mathrm{~m}$ overburden. Figure $7 \mathrm{~d}, 7 \mathrm{e}$, and $7 \mathrm{f}$ shows the same responses, but normalized to a $1 \mathrm{~S} / \mathrm{m}$ host seafloor half-space. Similar to the in-loop configuration, at early time the responses for different overburden depths are clearly resolved. Moreover, this early time effect is again independent of the conductor thickness. Observe that at later times the responses for different conductor thicknesses are also resolvable, and occur at scales of $1 \mathrm{nV} / \mathrm{A} \times \mathrm{m}^{2}$ and below. These responses will scale with the moment of the transmitting loop. We may conclude from these results that the coincident loop configuration is a useful tool to determine the overburden depth to a conductor and its thickness, although the latter requires a large dynamic range and low noise levels. Again, we must stress that the required noise level to determine overburden depths and conductor thicknesses is no more than a guide to instrumental design. It may or may not be possible to achieve these levels in practice.

It is interesting to compare the central loop response of model B in marine and land environments. In the marine environment, the upper half space has a finite conductivity while on land the upper half space is a perfect insulator. Figure $8 \mathrm{a}$ and $8 \mathrm{~b}$ compares the marine and land response of a $5 \mathrm{~m}$ conductor underlying an overburden whose thickness ranges from 0 to $5 \mathrm{~m}$, for the in-loop and coincident loop systems, respectively. The range of induced voltages is similar for both cases. However, in the absence of the conductive seawater, the voltage decays more rapidly, occurring at earlier times. This would be expected from the inclusion of a resistive upper halfspace. The onset of the decay occurs almost a decade earlier in the case of the $5 \mathrm{~m}$ overburden. Observe also that in the case of the inloop system, the voltage at very early times is nonzero for the landcase, although in the marine case it approaches zero. This is because the conductive seawater prevents the fields from reaching the receiver at very early times, whereas on land, the field - neglecting displacement currents - arrives at the center of the loop instantaneously. Furthermore, when the overburden is not present, the marine and land responses are almost identical after about $10 \mu \mathrm{s}$.

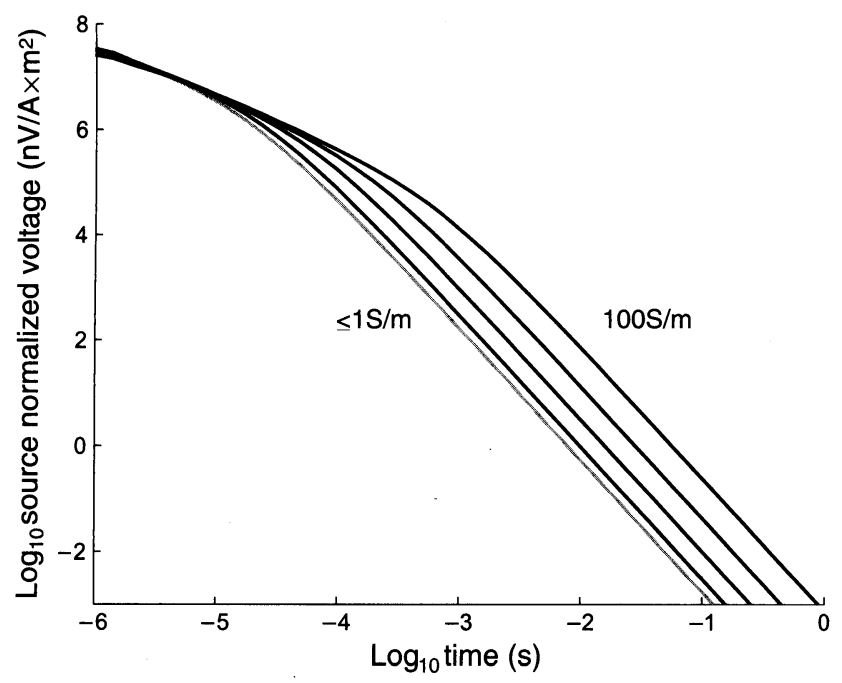

Figure 6. The coincident loop response of model A. The seafloor conductivity ranges logarithmically with values of $1 \mathrm{~S} / \mathrm{m}$ (gray), $3 \mathrm{~S} / \mathrm{m}, 10 \mathrm{~S} / \mathrm{m}, 30 \mathrm{~S} / \mathrm{m}$ and $100 \mathrm{~S} / \mathrm{m}$ (only $1 \mathrm{~S} / \mathrm{m}$ and $100 \mathrm{~S} / \mathrm{m}$ notated). Note that all responses for seafloor conductivities less than $1 \mathrm{~S} / \mathrm{m}$ will be identical to the $1 \mathrm{~S} / \mathrm{m}$ gray curve.
This can be understood by considering that the seawater and the air appear as resistive half spaces when compared to the conductive zone. The introduction of an overburden layer results in opposite conductivity contrasts above and below the source for the marine and land cases: while the air still appears as a resistive half-space, the seawater now appears as a conductive half-space with respect to the overburden. At later times, when the response is sensitive to the conductor depth, the marine and land responses are nearly identical. At these times, the fields have already propagated through the upper medium, be it seawater or air. Consequently, the late time response of the conductor is relatively unaffected by the presence of conductive seawater or resistive air. The practical implications of these results are important when considering instrumental design: a seafloor in-loop or coincident loop system need not measure times as early as the analogous system on land, while the length of the transient and the dynamic range should be similar in both cases.

\section{EIGENPARAMETER STATISTICAL ANALYSIS}

Let us now consider the resolving ability of the in-loop and coincident loop systems. Summarizing the technique as outlined by Edwards (1997), the investigation of the resolution by a given data set of a model parameter has to address a fundamental question of uniqueness. When one parameter of a model is changed, a change will be observed in the model type curve that passes through the data. If a certain parameter change moves the type curve, on average, just outside the errors on the data, it is tempting to state that the parameter is resolved to an accuracy which depends on size of this change. Unfortunately, the way in which the type curve is displaced need not be unique, and varying the value of a different model parameter, or the values of a particular group of model parameters, sometimes produces a very similar displacement. In such a case, one can not argue that the first model parameter is resolved by the data even though varying it does significantly alter the form of the type curve. The problem of this type of parameter intercorrelation is avoided by a technique known as eigenparameter statistical analysis (Edwards, 1997). The method provides a very clear, unambiguous set of statements for the interpreter, or the designer, of an experiment for assessing the errors and parameter intercorrelations in a multiparameter model determined from a synthetic or real data set with associated standard errors.

Results of an eigenparameter analysis of our particular problem may be displayed in a visual manner, as in Scholl and Edwards (2007). The relative weights of the original parameters contained in each eigenparameter are shown as circles of radii which are proportional to the weight; positive weights are shown as black circles while negative weights as white circles. Because we use the logarithm of the original parameters as components of the eigenparameters, an eigenparameter composed, for example, of a black and white circle of roughly equal size corresponds to a difference of the two log-parameters, and consequently to a quotient of the original parameters. Fractional standard errors of each eigenparameter are converted to percentage standard errors and are given along the left hand column of each figure. The coarse upper bounds of the percentage errors in the original parameters are given at the bottom of each figure.

We will consider four variations of model B in our eigenparameter analysis. The first is a thin $(1 \mathrm{~m})$ overburden and a thin $(5 \mathrm{~m})$ conductor, the second a thin $(1 \mathrm{~m})$ overburden and a thick $(30 \mathrm{~m})$ conductor, the third a thick $(5 \mathrm{~m})$ overburden and a thin $(5 \mathrm{~m})$ 
conductor, and the fourth a thick $(5 \mathrm{~m})$ overburden and a thick $(30 \mathrm{~m})$ conductor. We will first treat the conductivities of the overburden, conductor and basement as free parameters. We will then consider the effects of fixing their values, perhaps using available well log information or other a priori knowledge.
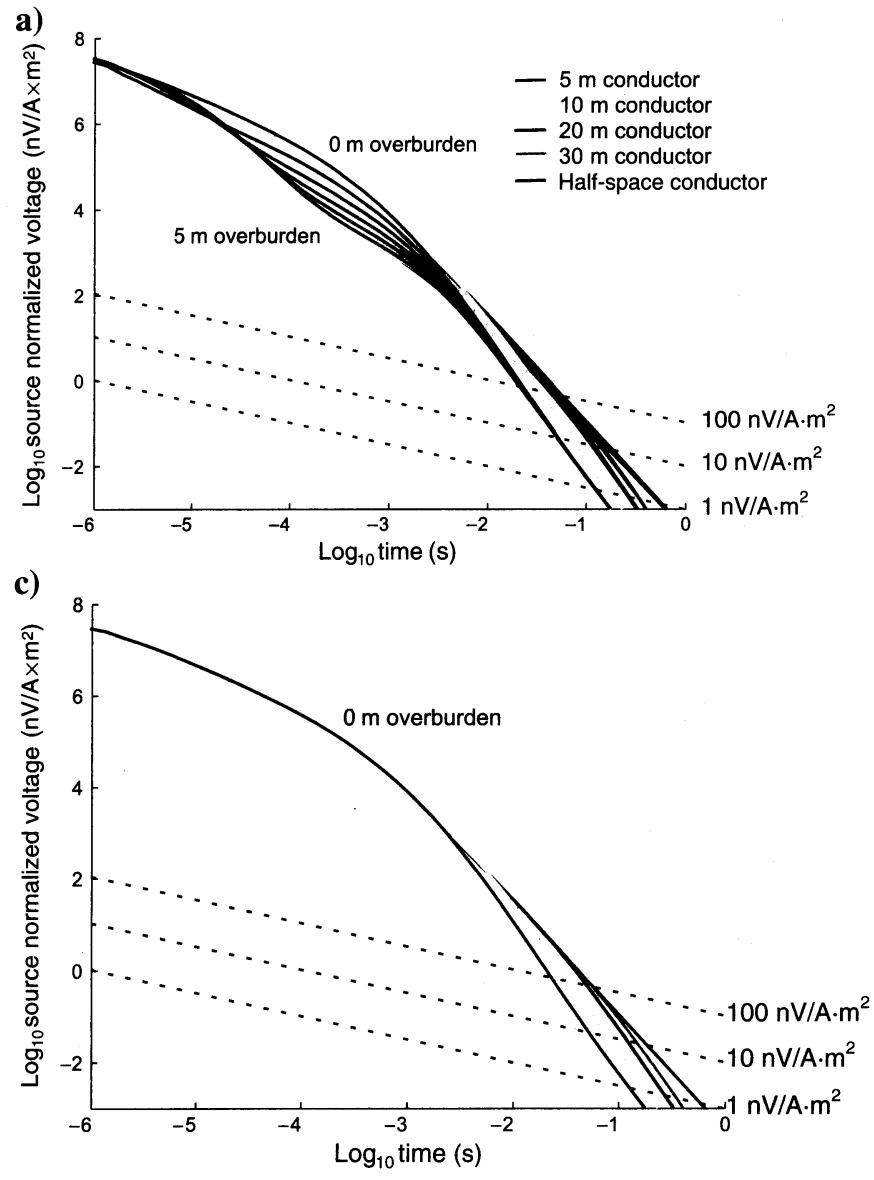

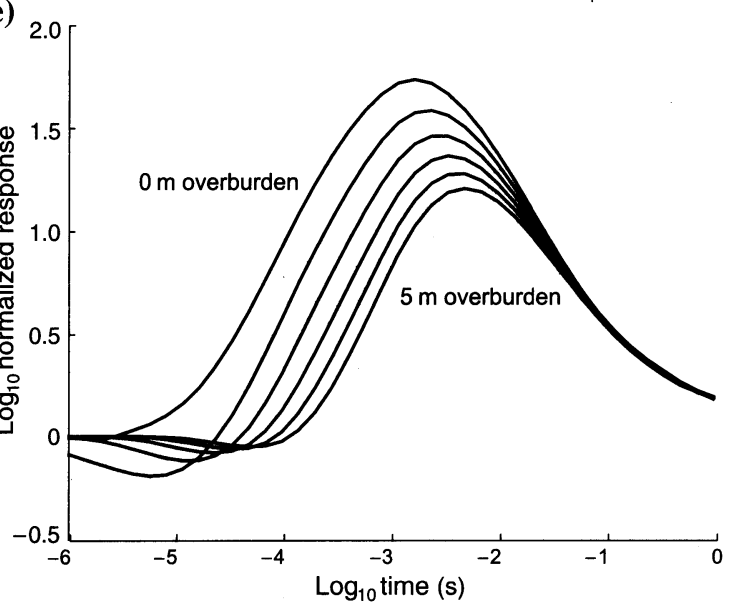

Figure 9 shows an eigenparameter analysis for the in-loop response of the four variations of model B. Percentage errors in the parameters are calculated assuming a data error inversely proportional to the square root of the time, approaching $1 \mathrm{nV} / \mathrm{A} \times \mathrm{m}^{2}$ at $1 \mathrm{~s}$, as discussed in the previous section. This choice of noise level
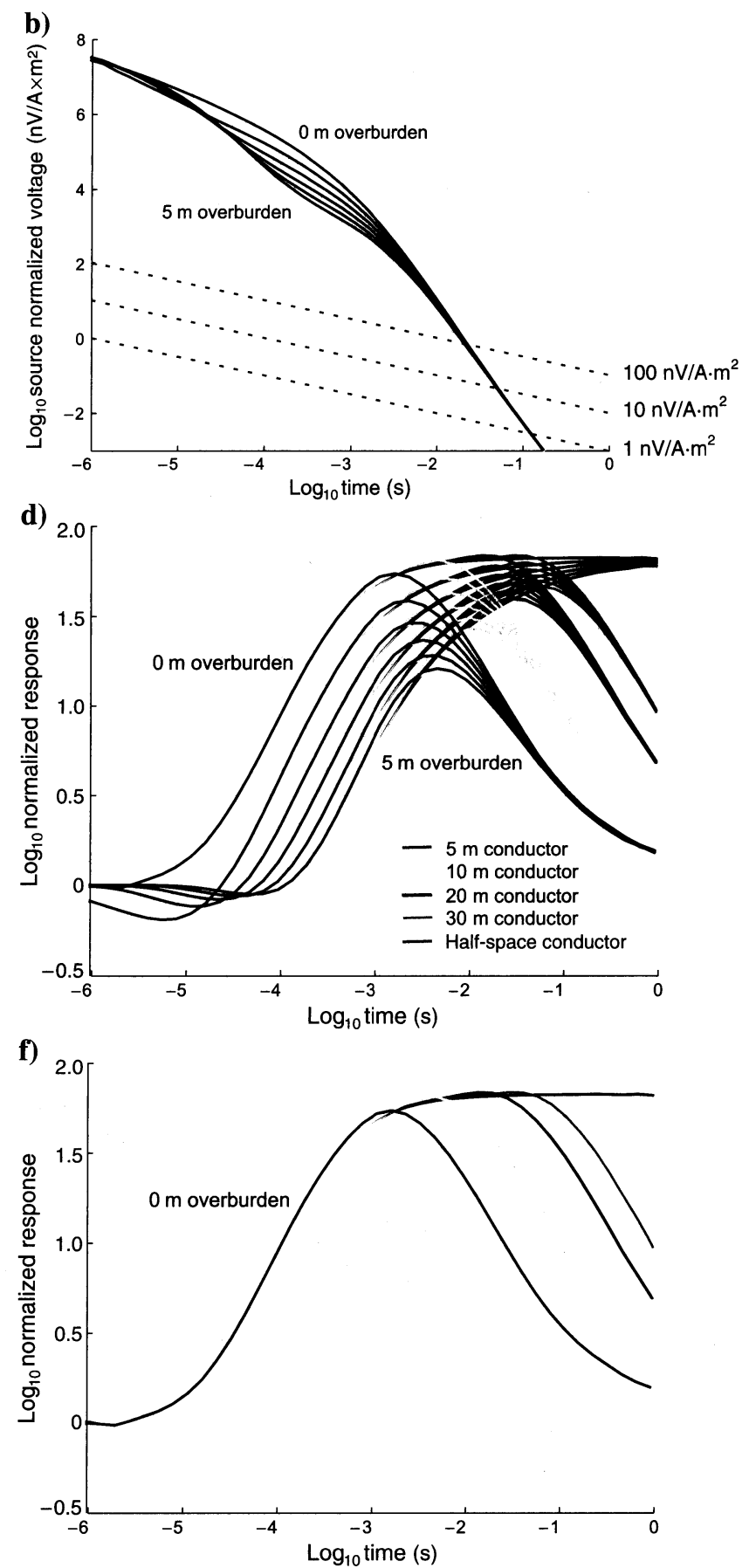

Figure 7. The coincident loop response of model B for different conductor thicknesses. The overburden depth ranges linearly from $0 \mathrm{~m}$ to $5 \mathrm{~m}$. (a) True response. (b) True response, showing only type curves of the $5 \mathrm{~m}$ conductor for varying overburden thickness. (c) True response, showing only type curves of the $0 \mathrm{~m}$ overburden model for varying conductor thicknesses. (d) True response normalized by a $1 \mathrm{~S} / \mathrm{m}$ seafloor half space. (e) Normalized response of the $5 \mathrm{~m}$ conductor. (f) Normalized response of the $0 \mathrm{~m}$ overburden model. Also shown on (a), (b), and (c) are three source normalized error floors, each inversely proportional to the square root of the time, approaching $1 \mathrm{nV} / \mathrm{A} \times \mathrm{m}^{2}, 10 \mathrm{nV} / \mathrm{A} \times \mathrm{m}^{2}$ and $100 \mathrm{nV} / \mathrm{A} \times \mathrm{m}^{2}$ at $1 \mathrm{~s}$, respectively. Note that these error floors are an order of magnitude higher than the in-loop case (Figure 5). 
is derived from land-based loop measurements by Munkholm and Auken (1996). If marine loop measurements exhibit higher or lower noise levels remains an open question. For the thin overburden, thin conductor model (Figure 9a), the overburden and conductor conductivity are intercorrelated, but the other parameters are for the most part not. The upper bound of the overburden thickness error is less than $1 \%$, while for the conductor thickness the error is approximately $170 \%$. However, as these errors scale with the signal to noise ratio, a tenfold increase in the transmitter loop size, the transmitter current or the receiver coil size, or a tenfold decrease in the noise floor will result in an error of $17.0 \%$. For example, a $50 \mathrm{~m}^{2}$ transmitting loop with $20 \mathrm{~A}$ of current and a $10 \mathrm{~m}^{2}$ receiving coil will require an absolute noise floor of less than $1 \times 10^{3} \mathrm{nV}$ at $1 \mathrm{~s}$ to resolve the base of a thin conductor, while the noise floor may be over $1 \times 10^{5} \mathrm{nV}$ and the system will still resolve the overburden thickness (here we consider a parameter resolved when its error is better than $10 \%$ ). For the thin overburden, thick conductor model (Figure 9b), the intercorrelations are the same. However, while the error in overburden thickness is still less than $1 \%$ the error in the conductor thickness is very large; the signal to noise ratio must be increased by at least five orders of magnitude for this parameter to be resolved to an accuracy of better than $10 \%$. This implies that a $50 \mathrm{~m}^{2}$ transmitting loop with $20 \mathrm{~A}$ of current and a $10 \mathrm{~m}^{2}$ receiving coil will require an absolute noise floor of $1 \mathrm{nV}$ at $1 \mathrm{~s}$ to resolve the base of a thick conductor, while the noise floor may be over $1 \times 10^{5} \mathrm{nV}$ and the system will still resolve the overburden thickness. For the analogous cases with a thick overburden (Figure 9c and 9d), the parameters are almost entirely independent. The errors in overburden thickness are approximately $4 \%$, while the errors in conductor thickness are very large. In the case of the thick conductor, a noise floor of $1 \mathrm{nV}$ is required to resolve its base to an accuracy of better than 10\%; however, for the thin conductor, a noise floor of $1 \times 10^{2} \mathrm{nV}$ would be sufficient. We can conclude that the in-loop configuration has the potential to be a mapping tool to determine overburden depth. In contrast, noise floors in the order of $1 \mathrm{nV}$ are required to map the base of a conductor over a few meters deep. Looking closely at Figure 9, we see that the conductor thickness and the basement conductivity are slightly correlated. The extremely large errors in the basement conductivity propagate into the errors of the conductor thickness. We may avoid this issue by fixing the conductivities of the layers. When the conductivities of the overburden, conductor and basement are fixed, the thickness of the overburden and conductor are uncorrelated for all model variations. Table 1a shows the error bounds for the depth of the overburden and the thickness of the conductor for this particular situation. The errors in the overburden depth are reduced on average by a factor of about 2.5 while the errors in the thickness of a thin conductor are reduced by a factor of three or more. It should be noted that although our results scale with the size of the transmitter loop and the number of wire turns in the coil, only a few orders of magnitude would probably be achievable due to inductive effects caused by a large amount of windings.

Figure 10 shows an eigenparameter analysis for the coincident loop response of the four variations of model B. Errors are again calculated assuming an error inversely proportional to the square root of the time, approaching $1 \mathrm{nV}$ at $1 \mathrm{~s}$. For the first variation (Figure 10a), the five model parameters are independently resolved to a fair degree, although there is some intercorrelation between the overburden thickness and the conductivity of the overburden and conductor. The same is true for the second variation (Figure 10b). However, although in both cases, the error in the overburden depth is small, the error in the conductor thickness is approximately $4 \%$ in the case of the thin conductor but over $2000 \%$ in the case of the thick conductor. As these error estimates scale with the signal to noise ratio, an increase in the size of the transmitter moment by two and a half orders of magnitude will result in an error of $10 \%$. For example, a $50 \mathrm{~m}^{2}$ transmitting loop with $20 \mathrm{~A}$ of current will require an absolute noise floor of less than $1 \times 10^{1} \mathrm{nV}$ at $1 \mathrm{~s}$ to resolve the base of a thick conductor, while it will only require a noise floor of $1 \times 10^{6} \mathrm{nV}$ to resolve the overburden thickness. For the third variation (Figure 10c), the overburden thickness and conductivity are intercorrelated, while the
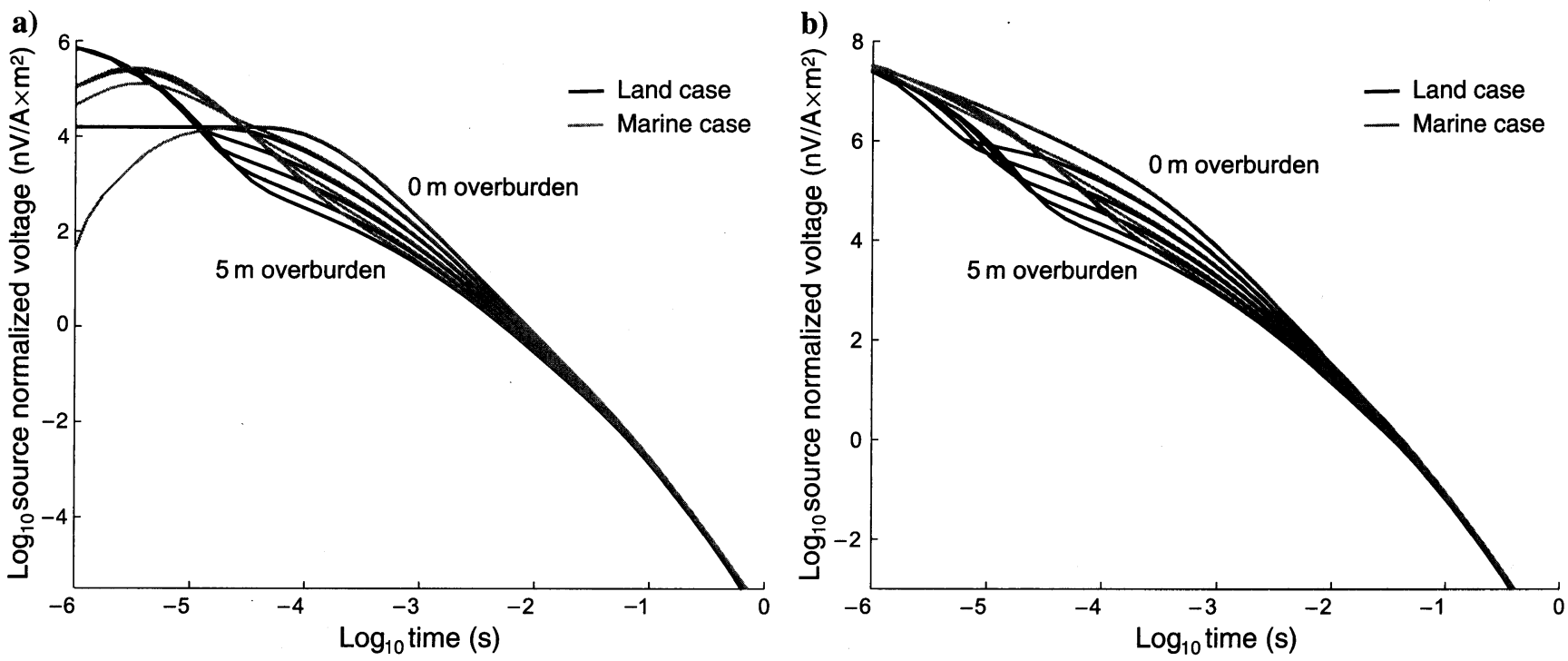

Figure 8. Comparison of the marine and land response of model B for (a) an in-loop system and (b) a coincident loop system. The overburden depth ranges linearly from 0 to $5 \mathrm{~m}$. The conductor is $5 \mathrm{~m}$ thick. For shallow structures, changes in type curves occur at later times in the marine case, which should facilitate instrumental design. 
a)

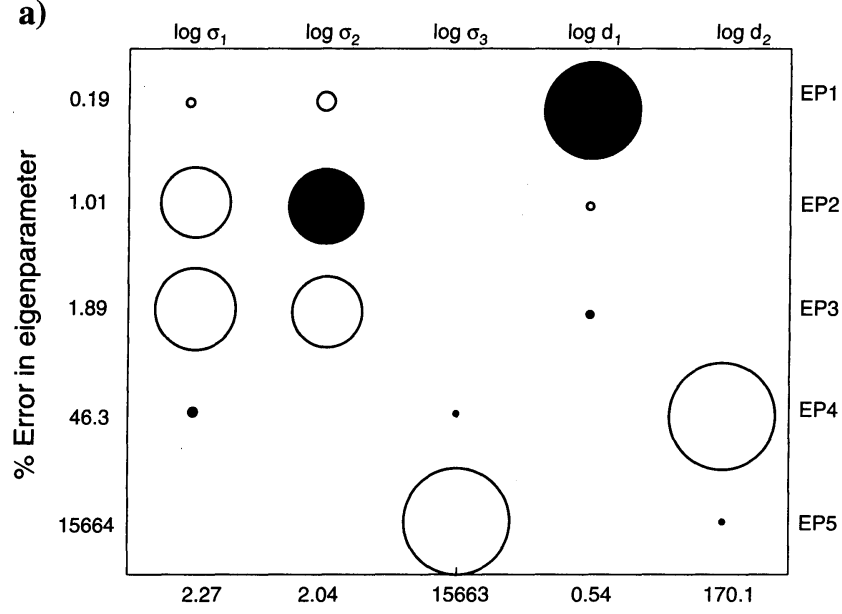

c)

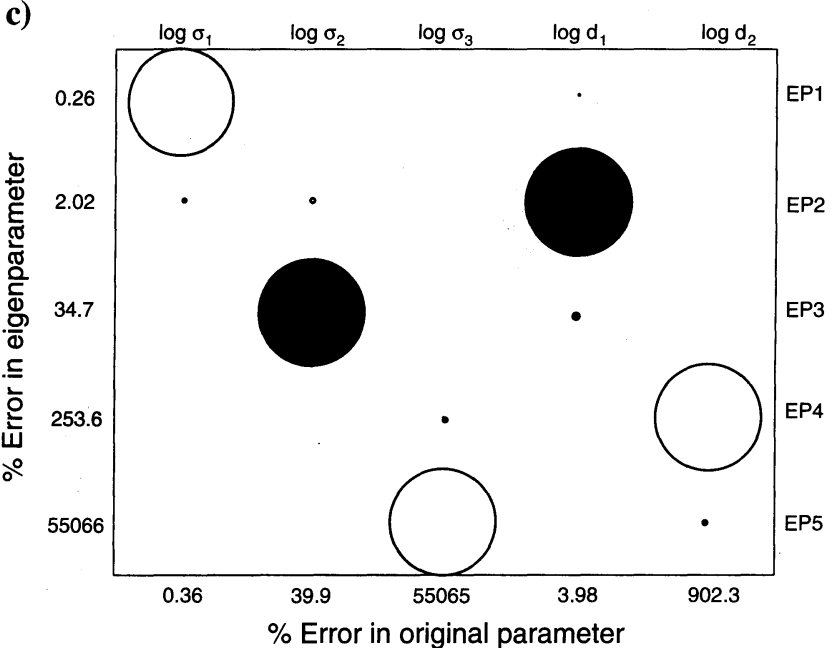

b)

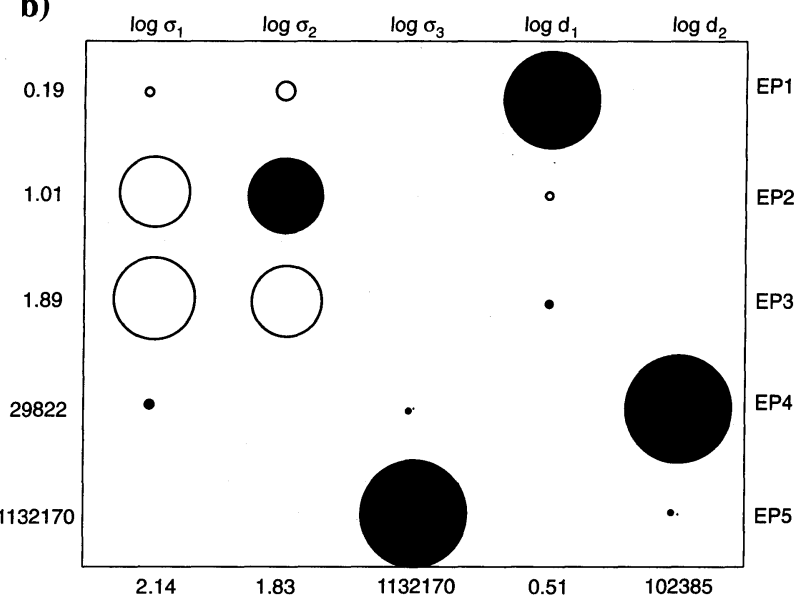

d)

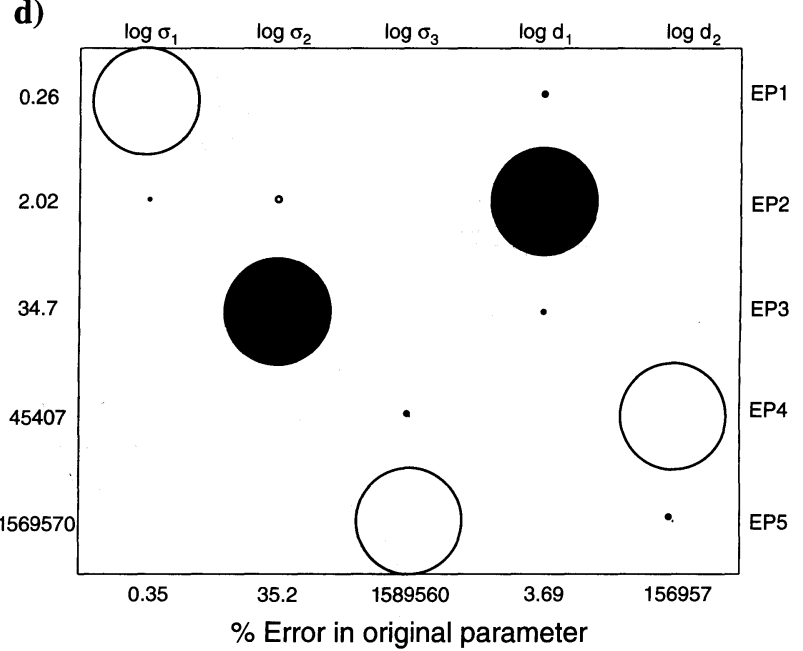

\section{Legend}

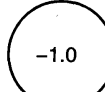

Figure 9. Eigenparameter analysis for the in-loop response of model B: (a) $1 \mathrm{~m}$ overburden and $5 \mathrm{~m}$ conductor, (b) $1 \mathrm{~m}$ overburden and $30 \mathrm{~m}$ conductor, (c) $5 \mathrm{~m}$ overburden and $5 \mathrm{~m}$ conductor, (d) $5 \mathrm{~m}$ overburden and $30 \mathrm{~m}$ conductor.

Table 1. The percentage error bounds for the depth of the overburden and the thickness of the conductor, when the conductivities of the overburden, conductor and basement are fixed.

In-loop configuration

\begin{tabular}{|c|c|c|c|c|c|c|c|c|}
\hline & \multicolumn{2}{|c|}{$d_{1}=1 \mathrm{~m}, d_{2}=5 \mathrm{~m}$} & \multicolumn{2}{|c|}{$d_{1}=1 \mathrm{~m}, d_{2}=30 \mathrm{~m}$} & \multicolumn{2}{|c|}{$d_{1}=5 \mathrm{~m}, d_{2}=5 \mathrm{~m}$} & \multicolumn{2}{|c|}{$d_{1}=5 \mathrm{~m}, d_{2}=30 \mathrm{~m}$} \\
\hline Error $d_{2}$ & 170.1 & 45.9 & 102,385 & 29,822 & 902.3 & 253.5 & 156,957 & 45,406 \\
\hline \multicolumn{9}{|c|}{ Coincident loop configuration } \\
\hline Error $d_{2}$ & 4.10 & 1.06 & 2097 & 597.3 & 19.5 & 5.39 & 3174 & 908.2 \\
\hline
\end{tabular}


remaining parameters can be independently resolved. The error in the overburden depth is small and the error in the conductor thickness is approximately $20 \%$. For the fourth variation (Figure 10d), the overburden conductivity and thickness are intercorrelated as are the conductor thickness and basement conductivity. The error in the overburden thickness is small while the error in the conductor thickness is over $100 \%$. Again, as the parameter errors scale with the signal to noise ratio, we can conclude that the coincident loop configuration is a useful tool to map the overburden depth to the conductor, as well as the base of a thin conductor. However, a high signal to noise ratio is required to map the base of a thick conductor an accuracy of better than 10\%. Looking closely at Figure 10, we see that the conductor thickness and the basement conductivity are slightly correlated. The extremely large errors

a)

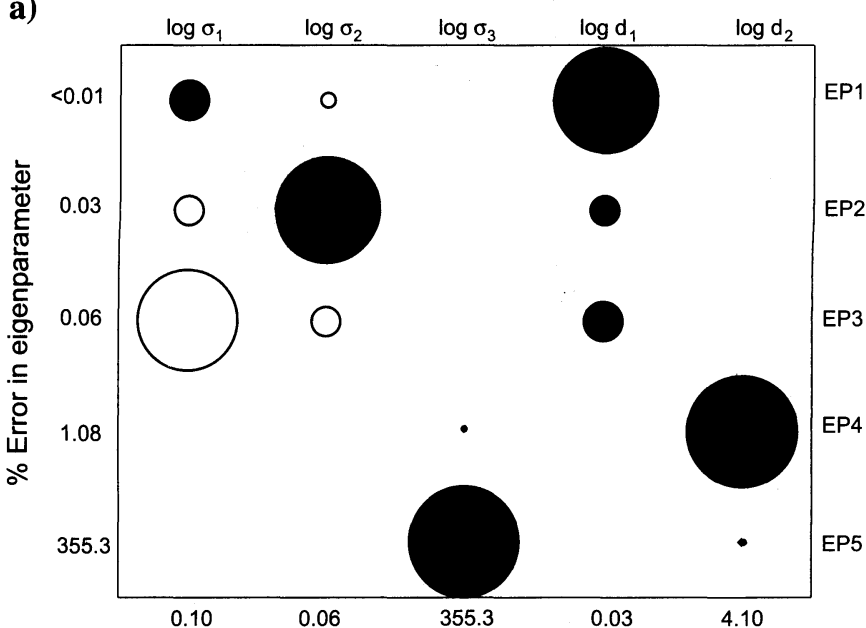

c)

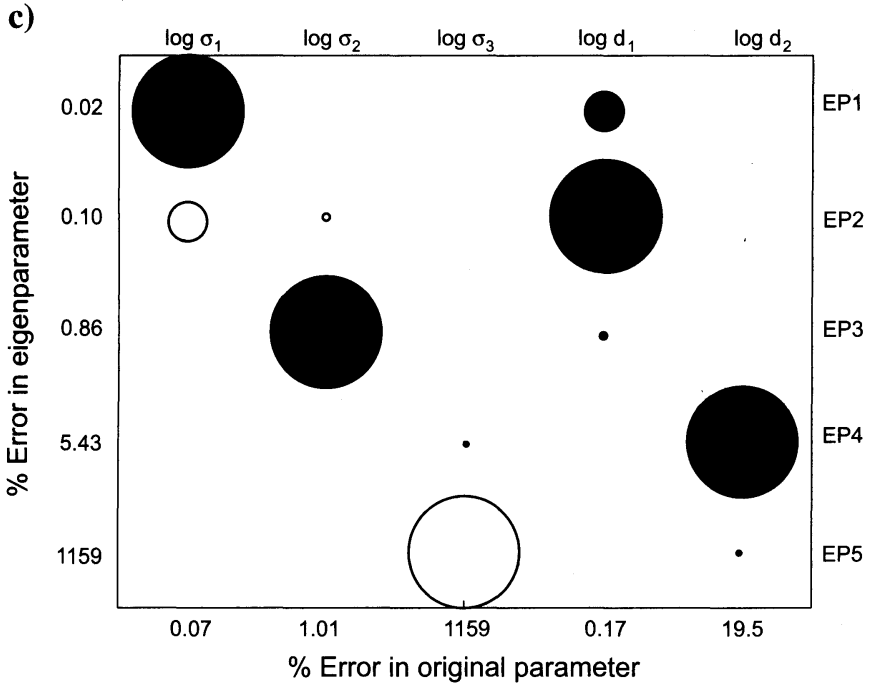

in the basement conductivity propagate into the errors in the conductor thickness. When the conductivities of the overburden, conductor and basement are fixed, the thickness of the overburden and conductor are uncorrelated for all model variations. Table $1 \mathrm{~b}$ shows the error bounds for the depth of the overburden and the thickness of the conductor for this particular situation. The error in the conductor thickness is reduced by almost a factor of two for the thick overburden, thick conductor case. The errors in the overburden depth are reduced by approximately a factor of two while the errors in the thickness of the conductor are reduced by a factor of three or more. The practical implications of this result are important; the noise floor required to detect the base of a conductor using a coincident loop system increases by a factor of three when the conductivites of the overburden, conductor, and host are known.

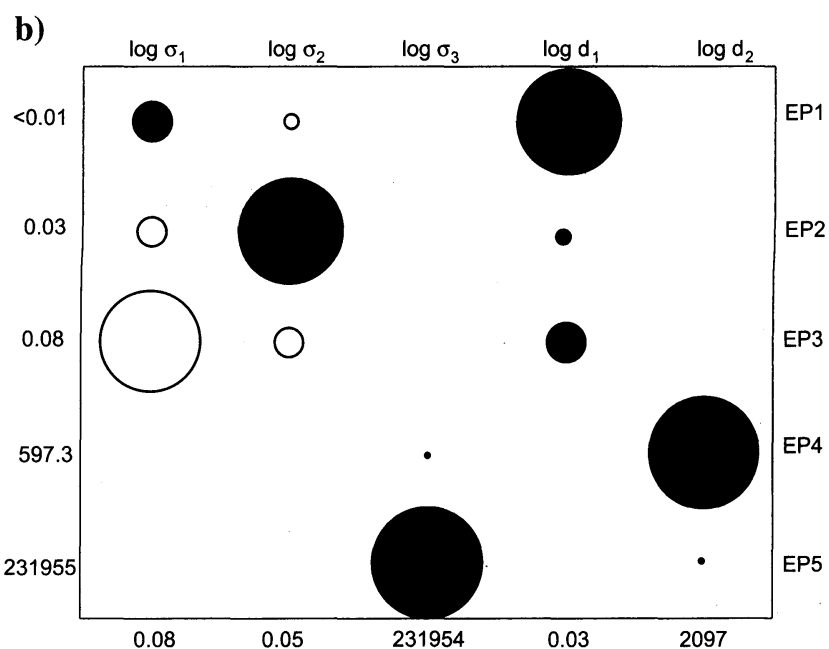

d)

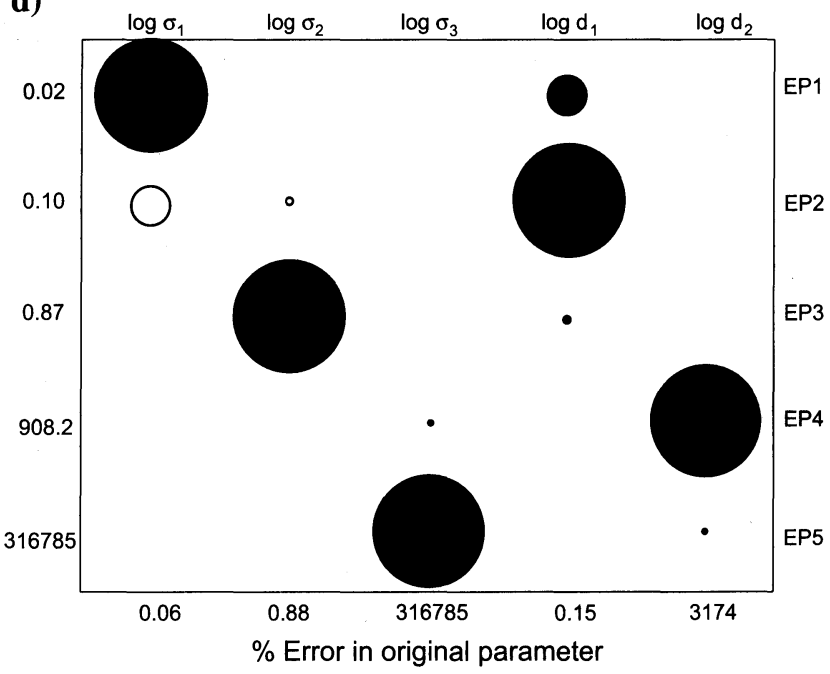

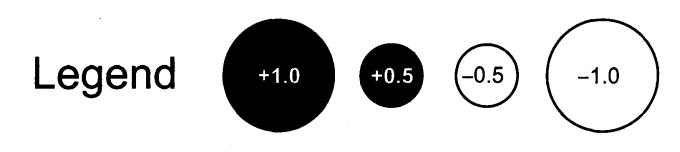

Figure 10. Eigenparameter analysis for the coincident loop response of model B: (a) $1 \mathrm{~m}$ overburden and $5 \mathrm{~m}$ conductor, (b) $1 \mathrm{~m}$ overburden and $30 \mathrm{~m}$ conductor, (c) $5 \mathrm{~m}$ overburden and $5 \mathrm{~m}$ conductor, (d) $5 \mathrm{~m}$ overburden and $30 \mathrm{~m}$ conductor. 


\section{CONCLUSIONS}

Transient electromagnetic measurements with concentric horizontal loops in marine environments have up to now received little attention by the electromagnetic community. However, in this paper, we show that in marine mineral exploration, the in-loop and the coincident loop configuration are useful tools to determine an anomalous zone of increased conductivity and consequently give drill targets. It also is possible that such systems may be useful in determining the overburden depth to a conductive target as well as its thickness; however, this result may be overly optimistic depending on the degree of geological complexity. For example, the coincident loop configuration with a $50 \mathrm{~m}^{2}$ transmitting loop and $20 \mathrm{~A}$ of current will require an absolute noise floor between 1 and $10 \mathrm{nV}$ at $1 \mathrm{~s}$ to resolve the base of a $30 \mathrm{~m}$ thick conductor to an accuracy of better than $10 \%$. However, the noise floor may be as much as five orders of magnitude higher and the system will still resolve a $5 \mathrm{~m}$ overburden. These signal to noise levels may be achievable in practice, considering the current airborne systems with output currents of $100 \mathrm{~A}$ and switch off times of the order of $10 \mu \mathrm{s}$, or the lightweight marine CSEM-system currently developed at the IFMGEOMAR with output currents of up to $80 \mathrm{~A}$. The very low errors in the overburden depth and conductivity from our error analysis are probably unrealistic. This is because the early times central loop response is very sensitive to shallow structure, and systematic errors in instrumentation, such as delayed switch times, will result in large errors at early times. These errors will likely be far larger than the random noise model used in this analysis. A more proper error model would be to have a relative data error at very early times (perhaps of the order of $1 \%$ ), followed by noise model following a decay proportional to the inverse of the off-time. It should be stressed that our conclusions concerning the noise floors required to determine overburden depths and conductor thicknesses should be considered as a guide to those interested in experimental design of a central loop system. A system which, under optimal conditions, has a signal to noise ratio lower than those shown to be necessary will have no chance in establishing the base of a conductor or its conductivity. In fact, under real conditions the determination of layer depths and conductivities will be difficult even for an adequately designed system, due to factors such as geologic complexity, seafloor bathymetry, and so on.

However, we speculate that for central loop systems 3D effects of the ore deposit at depth will be smaller than for regular marine CSEM systems because a coincident loop system only samples a small volume of seawater and conductive ocean floor surrounding the loop. For our proposed experiment, this implies that a simple 1D interpretation should be sufficient for first pass mapping studies. This simplification is already commonly used for land-based applications. However, rugged topography of the seafloor in the vicinity of the loop system may cause distortion and needs to be tested by appropriate 3D modeling. On the seafloor a coincident loop system will undoubtedly suffer from noise induced by instrument vibrations in the earth's magnetic field. However, because the measurement times of interest are in the submillisecond scale, we speculate that any lower frequency induction noise will have no effect on the interpretation as long as proper processing steps are performed. Whether or not such a system would have to remain stationary during measurements (similar to the GEOMAR experiment during Sonne cruise 214) or could be designed as a ROV-based flying system (similar to the GEOMAR experiment at the West Nile Delta) remains to be seen.

\section{ACKNOWLEDGMENTS}

The authors would like to thank Alan Chave for his helpful and thorough review, as well as the input from two anonymous referees. Andrei Swidinsky was supported by the German Ministry of Education and Research (BMBF) through the GEOTECHNOLOGIEN programme, project SUGAR-A, grant no. 03G0687. Sebastian Hölz was supported by RWE Dea.

\section{APPENDIX A}

\section{THE HORIZONTAL LOOP IN A LAYERED EARTH}

We wish to calculate the vertical magnetic field and the induced voltage of a horizontal transmitting loop with wire of radius $a$. A current $I$ within the loop is abruptly switched off at a time $t=0$. The loop lies within a stack of layers above and below it. The center of the loop is at the origin of cylindrical coordinates $(r, \phi, z)$. It is located within a very thin layer that has a conductivity $\sigma_{0}$. The conductivities and thicknesses of $N$ layers below the source layer and $M$ layers above it are denoted by subscripts $i$ and $j$ on symbols $\sigma$ and $d$, respectively. Indices $i$ and $j$ increase away from the source, starting from unity (Figure A-1). The problem is axisymmetric. The one and only azimuthal electric field component $E_{\phi}(r, z)$ satisfies the Helmholtz differential equation in Laplace domain,

$$
\begin{aligned}
& \frac{\partial^{2} E_{\phi}(r, z)}{\partial r^{2}}+\frac{1}{r} \frac{\partial E_{\phi}(r, z)}{\partial r}-\frac{E_{\phi}(r, z)}{r^{2}}+\frac{\partial^{2} E_{\phi}(r, z)}{\partial z^{2}} \\
& \quad=\alpha^{2} E_{\phi}(r, z),
\end{aligned}
$$

where $\alpha^{2}=s \mu_{0} \sigma$ within any source free layer. Let us define a Hankel transform relating fields such as $E_{\phi}(r, z)$ and $e_{\phi}(\lambda, z)$ as

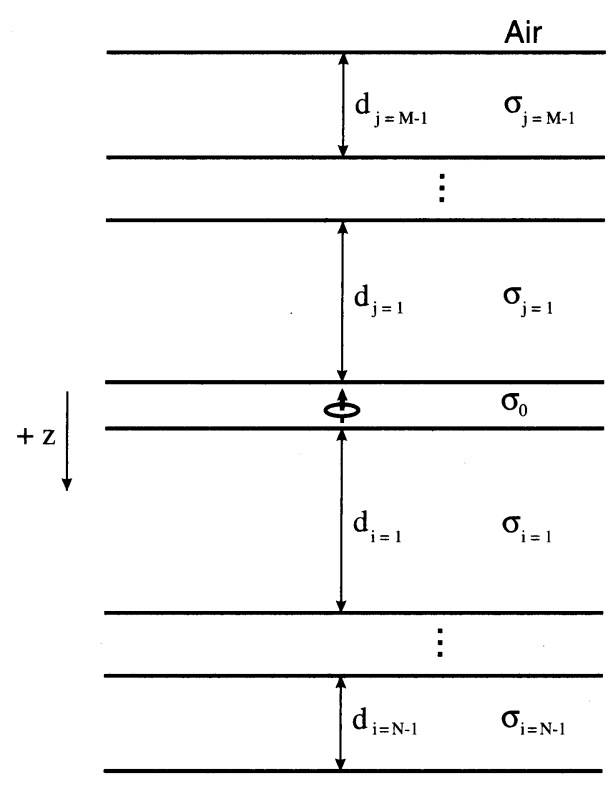

$\sigma_{\mathrm{N}}$

Figure A-1. Sketch of the geometry for the derivation of the fields of a loop source. 


$$
E_{\phi}(r, z)=\int_{0}^{\infty} \lambda e_{\phi}(\lambda, z) J_{1}(\lambda r) d \lambda
$$

where $J_{1}$ is a Bessel function of the first kind of order one. Substituting equation A-2 into A-1, taking the derivatives with respect to $r$ and $z$, and canceling the integrals and common variables present on both sides of the new equation yields

$$
\begin{aligned}
& {\left[\lambda^{2} J_{1}^{\prime \prime}(\lambda r)+\frac{\lambda}{r} J_{1}^{\prime}(\lambda r)-\frac{1}{r^{2}} J_{1}(\lambda r)\right] e_{\phi}(\lambda, z)+\frac{\partial^{2} e_{\phi}(\lambda, z)}{\partial z^{2}} J_{1}(\lambda r)} \\
& \quad=\alpha^{2} e_{\phi}(\lambda, z) J_{1}(\lambda r),
\end{aligned}
$$

where the prime indicates differentiation with respect to $\lambda r$. The term in the square brackets in equation A-3 can be.identified as Bessel's equation of order one, and is equal to $-\lambda^{2} J_{1}(\lambda r)$ (Abramowitz and Stegun [1972], equation 9.1.1, p. 358) Substituting this into the square brackets in equation A-3, canceling the Bessel functions, rearranging and removing the explicit dependence on $(\lambda, z)$ for clarity yields the simple second order equation

$$
\frac{\partial^{2} e_{\phi}}{\partial z^{2}}-\theta^{2} e_{\phi}=0
$$

where $\theta^{2}=\lambda^{2}+\alpha^{2}$. A solution of differential equation A-4 in any lower layer $i$, of constant conductivity $\sigma_{i}$ and thickness $d_{i}$, is

$$
e_{\phi, i}=U \cosh \left(\theta_{i} z\right)+W \sinh \left(\theta_{i} z\right)
$$

where $U$ and $V$ are functions independent of $z$ constrained by the boundary conditions. The radial magnetic field $b_{r}$ is related to the electric field by Faraday's law, $s b_{r}=\partial e_{\phi} / \partial z$ so that

$$
s b_{r, i}=\theta_{i}\left[U \sinh \left(\theta_{i} z\right)+W \cosh \left(\theta_{i} z\right)\right] .
$$

Eliminating $U$ and $W$ from equations A-5 and A-6, enforcing the continuity of $e_{\phi}$ and $b_{r}$ at the boundaries of the layer and rearranging generates an upward recursion relationship,

$$
Q_{i}=\frac{\mu_{0}}{\theta_{i}}\left[\frac{\theta_{i} Q_{i+1}+\mu_{0} \tanh \left(\theta_{i} d_{i}\right)}{\mu_{0}+\theta_{i} Q_{i+1} \tanh \left(\theta_{i} d_{i}\right)}\right]
$$

where the symbol $Q$ denotes the ratio $-\mu_{0} e_{\phi} / s b_{r}$, and $Q_{i}$ and $Q_{i+1}$ are the specific values of $Q$ at the top and bottom of the $i$ th layer. For any given $\lambda$ the value of $Q$ just below the source layer $Q_{1}$ can be obtained by successive applications of expression A-7 from a starting value at the top of the lower half-space given by

$$
Q_{N}=\frac{\mu_{0}}{\theta_{N}}
$$

A similar argument applies to the derivation of the downward recursion relation, equation 3 . However, there are two subtle differences. First, the symbol $P$ denotes the ratio $\mu_{0} e_{\phi} / s b_{r}$, conveniently chosen in this case to be positive. Secondly, because the upper halfspace is air, $\alpha^{2}=s^{2} \mu_{0} \varepsilon_{0}$ in this medium. This represents wave propagation in the nearly perfect insulator. For deep water, this term is negligible. However, for extremely shallow water applications, displacement currents may become a relevant issue.
The functions $P$ and $Q$ are continuous across all layer boundaries in regions above and below the source, respectively, but they are discontinuous across the source layer because of the effect of the magnetic dipole source. Although the electric field is continuous through the source layer, the radial magnetic field is not because it switches sign across the layer. From the definitions of $P$ and $Q$, the amount $\delta b_{r}$ by which $b_{r}$ below the source layer exceeds the value above may be written as

$$
\delta b_{r}=b_{r, \text { below }}-b_{r, \text { above }}=\left(\frac{1}{P_{1}}+\frac{1}{Q_{1}}\right) \frac{\mu_{0} e_{\phi, 1}}{s} .
$$

The magnetic field of a loop of radius $a$ in a medium of conductivity $\sigma_{0}$ is given in Ward and Hohmann (1987) and other classic texts as

$$
b_{r}= \pm \frac{I a \mu_{0}}{2} J_{1}(\lambda a) e^{-\theta_{0}|z|}
$$

Recalling that regions below the source are in the positive $z$-direction, the discontinuity $\delta b_{r}$ by which $b_{r}$ below the source layer exceeds the value above may then be found to be

$$
\delta b_{r}=b_{r, \text { below }}-b_{r, \text { above }}=\mu_{0} I a J_{1}(\lambda a) .
$$

If expressions A-9 and A-11 are equated, an expression for $e_{\phi, 1}$ in terms of the layered structure is obtained as

$$
e_{\phi, 1}=\operatorname{sIaJ}_{1}(\lambda a)\left[\frac{P_{1} Q_{1}}{P_{1}+Q_{1}}\right]
$$

In the space domain, the azimuthal electric field can then be written as

$$
E_{\phi, 1}=\operatorname{sIa} \int_{0}^{\infty}\left[\frac{P_{1} Q_{1}}{P_{1}+Q_{1}}\right] \lambda J_{1}(\lambda a) J_{1}(\lambda r) d \lambda
$$

The vertical magnetic field $B_{z, 1}$ can be found from expression A-13 using Faraday's law, given in cylindrical coordinates as.

$$
B_{z, 1}=(1 / s) \frac{1}{r} \frac{\partial}{\partial r} r E_{\phi 1} .
$$

Performing the differentiation and using the identity $J_{1}^{\prime}(x)=$ $J_{0}(x)-J_{1}(x) / x$ we can write the expression for $B_{z, 1}$ as

$$
B_{z, 1}=I a \int_{0}^{\infty}\left[\frac{P_{1} Q_{1}}{P_{1}+Q_{1}}\right] \lambda^{2} J_{1}(\lambda a) J_{0}(\lambda r) d \lambda
$$

The magnetic field at the center of the loop can be found by setting $r=0$ in equation A-15. Using the identity $J_{0}(x) \rightarrow 1$ as $x \rightarrow 0$, we obtain the in-loop response as 


$$
B_{z, 1}=I a \int_{0}^{\infty}\left[\frac{P_{1} Q_{1}}{P_{1}+Q_{1}}\right] \lambda^{2} J_{1}(\lambda a) d \lambda
$$

To calculate the induced voltage in a small loop of radius $b$ located at the center of a loop of current abruptly switched off, we multiply expression A-16 by $\pi b^{2}$, the area of the receiving loop and obtain expression 1 . If the receiving loop is coincident with the transmitting loop, the induced voltage in the loop is the negative time rate of change of the flux through the loop. In the Laplace domain, we may write

$$
V=-s \int_{0}^{a} \int_{0}^{2 \pi} B_{z, 1} r d r d \phi .
$$

Using the identity $\int x J_{0}(x) d x=x J_{1}(x)$, we obtain

$$
V=2 \pi I a^{2} s \int_{0}^{\infty}\left[\frac{P_{1} Q_{1}}{P_{1}+Q_{1}}\right] \lambda\left[J_{1}(\lambda a)\right]^{2} d \lambda .
$$

To calculate the induced voltage of a loop of current abruptly switched off, we multiply expression A-18 by the Laplace transform of a step function, $1 / \mathrm{s}$, and obtain expression 2 .

\section{APPENDIX B}

\section{THE EFFECT OF A LAYERED WATER COLUMN}

In certain cases, stable layering in the water column near the seafloor may lead to conductivity profiles which can have a significant influence on the response of central loop systems. Figure B-1 shows a profile of ionic concentration as a function of depth near the seafloor for the Kebrit Deep in the Red Sea (Schmitt et al., 2003). This profile has been observed to be stable over a period of several decades in terms of temperature, chlorinity and brine thickness (Hartmann et al., 1998). Similar situations can be found in the nearby Atlantis II Deep, which is currently being assessed for its economic potential with respect to marine sulfide deposits (Bertram et al., 2011). Direct measurements of the conductivity in these brine pools show extreme conductivity values $(>5 \mathrm{~S} / \mathrm{m}$ ), which could not be measured directly by regular CTD probes (Hartmann et al., 1998). Therefore, we estimate conductivities from geochemical analyses of samples taken directly within the brine. The average value of salt content in the ocean is approximately $35 \mathrm{~g} / \mathrm{L}$, which is close to what is observed in the upper portion of the particular profile in Figure B-1. As a simple approximation, the electrical conductivity of brine is proportional to the ionic concentration of the solution. Setting the electrical conductivity at the top of the profile to an average seawater value of $3 \mathrm{~S} / \mathrm{m}$, we can estimate the electrical conductivity as a function of depth from the ratio of the total dissolved solids at each depth interval (Figure B-1). Note the almost eight-fold increase of Figure B-1. in electrical conductivity in the lower $12 \mathrm{~m}$ directly above the seafloor due to the corresponding increase in ionic concentration. Figure B-2 shows the coincident loop response of a simple, uniform $10 \mathrm{~S} / \mathrm{m}$ seafloor with three different water column conductivity distributions. The first is a uniform seawater with a conductivity of $3 \mathrm{~S} / \mathrm{m}$. The second is a uniform seawater conductivity of $24 \mathrm{~S} / \mathrm{m}$ (the conductivity of the brine just above the seafloor in Figure B-1). The third is a layered seawater conductivity model

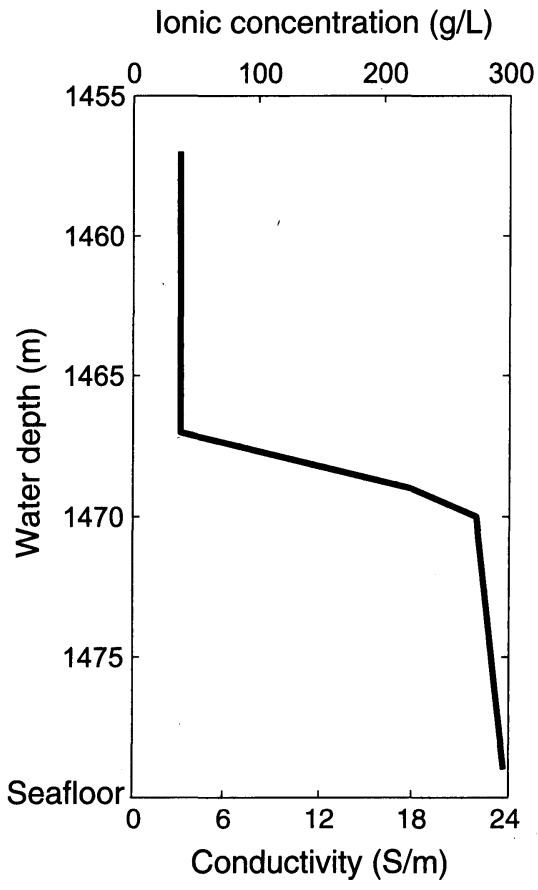

Figure B-1. Ionic concentration and calculated electrical conductivity of seawater as a function of depth, near the seafloor in the Kebrit Deep, Red Sea (Schmitt et al., 2003).

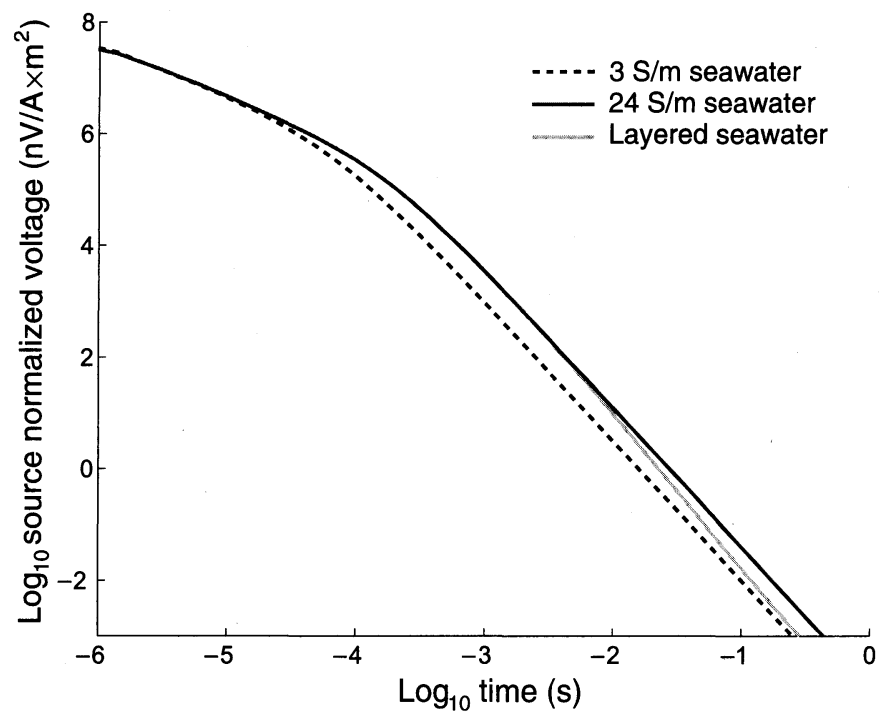

Figure B-2. Coincident loop response of a $10 \mathrm{~S} / \mathrm{m}$ uniform seafloor. Dashed black curve: $3 \mathrm{~S} / \mathrm{m}$ uniform seawater. Solid black curve: $24 \mathrm{~S} / \mathrm{m}$ seawater (maximum value from the profile in Figure B-1). Gray curve: Layered seafloor using conductivity profile 
corresponding to the profile calculated in Figure B-1. It is clear that the electromagnetic response in these three situations is significantly different. Consequently, in special cases where such thin and stable brine layers are known to exist near the seafloor, it is important to consider the effects of a layered electrical conductivity structure in the water column.

\section{REFERENCES}

Abramowitz, M., and I. A. Stegun, 1972, Handbook of mathematical functions with formulas, graphs and mathematical tables: National Bureau of Standards, 10th edition, Dover Publications Inc.

Anderson, W., 1979, Numerical integration of related Hankel transforms of orders 0 and 1 by adaptive digital filtering: Geophysics, 44, 1287-1305, doi: $10.1190 / 1.1441007$.

Bertram, C., A. Krätschell, K. O'Brien, W. Brückmann, A. Proelss, and K. Rehdanz, 2011, Metalliferous sediments in the Atlantis II Deep Assessing the geological and economic resource potential and legal constraints: Resources Policy, 36(4), 315-329, doi: 10.1016/j.resourpol.2011 .09 .001

Cairns, G., R. Evans, and R. Edwards, 1996, A time domain electromagnetic survey of the TAG hydrothermal mound: Geophysical Research Letters, 23, 3455-3458, doi: $10.1029 / 96$ GL03233.

Chave, A., 2009, On the electromagnetic fields produced by marine frequency domain controlled sources: Gephysical Journal International, 179, no. 3, 1429-1457, doi: 10.1111/j.1365-246X.2009.04367.x.

Chave, A., S. Constable, and R. Edwards, 1991, Electrical exploration methods for the seafloor, in M. Nabighian, and E. Neitzel, eds., Electromagnetic methods in applied geophysics - Volume 2, Applications: SEG, 931-966.

Chave, A., and C. Cox, 1982, Controlled electromagnetic sources for measuring electrical conductivity beneath the oceans: 1 . Forward problem and model study: Journal of Geophysical Research, 87, 5327-5338, doi: 10 .1029/JB087iB07p05327.

Cheesman, S., S. Heesman, R. Edwards, and A. Chave, 1987, On the theory of sea-floor conductivity mapping using transient electromagnetic systems: Geophysics, 52, 204-217, doi: 10.1190/1.1442296.

Christensen, N., 1990, Optimized fast Hankel transform filters: Geophysical Prospecting, 38, 545-568, doi: 10.1111/gpr.1990.38.issue-5.

Coggon, J., and H. Morrison, 1970, Electromagnetic investigation of the sea floor: Geophysics, 35, 476-489, doi: 10.1190/1.1440109.

Danielsen, J., E. Auken, F. Jørgensen, V. Sondergaard, and K. Sørensen, 2003, The application of the transient electromagnetic method in hydrogeophysical surveys: Journal of Applied Geophysics, 53, no. 4, 181-198, doi: 10.1016/j.jappgeo.2003.08.004.

Edwards, R., 1997, On the resource evaluation of marine gas hydrate deposits using sea-floor transient electric dipole-dipole methods: Geophysics, 62, 63-74, doi: 10.1190/1.1444146.

Edwards, R., and A. Chave, 1986, A transient electric dipole-dipole method for mapping the conductivity of the sea-floor: Geophysics, 51, 984-987, doi: 10.1190/1.1442156.

Edwards, R., L. Law, P. Wolfgram, D. Nobes, M. Bone, D. Trigg, and J. DeLaurier, 1985, First results of the MOSES experiment: Sea sediment conductivity and thickness determination, Bute Inlet, British Columbia, by magnetometric offshore electrical sounding: Geophysics, 50, 153160, doi: $10.1190 / 1.1441825$.

Ellingsrud, S., M. Sinha, S. Constable, T. Eidesmo, L. MacGregor, and S. Johansen, 2002, The meter reader - Remote sensing of hydrocarbon layers by sea bed logging (SBL): Results from a cruise offshore WestAfrica: The Leading Edge, 21, 972-982, doi: 10.1190/1.1518433.

Francis, T., 1985, Electrical methods in the exploration of seafloor mineral deposits, in P. Teleki, M. Dobson, J. Moore, and U. von Stackelberg, eds., Marine minerals: Springer, 413-420.

Grant, F., and G. F. West, 1965, Interpretation theory in applied geophysics: McGraw-Hill.

Hartmann, M., J. Scholten, P. Stoffers, and F. Wehner, 1998, Hydrographic structure of brine-filled deeps in the Red Sea - New results from the
Shaba, Kebrit, Atlantis II, and Discovery Deep: Marine Geology, 144, no. 4, 311-330, doi: 10.1016/S0025-3227(97)00055-8.

Herzig, P., and M. Hannington, 1995, Polymetallic massive sulfides at the modern seafloor - A review: Ore Geology Reviews, 10, no. 2, 95-115, doi: 10.1016/0169-1368(95)00009-7.

Hölz, S., D. Polag, M. Becken, R. Fiedler-Volmer, H. Zhang, K. Hartmann, and $\mathrm{H}$. Burkhardt, 2007, Electromagnetic and geoelectric investigation of the Gurinai structure, inner Mongolia, NW China: Tectonophysics, 445, 26-48, doi: 10.1016/j.tecto.2007.06.008.

Johansen, H., and K. Sørensen, 1979, Fast Hankel transforms: Geophysical Prospecting, 27, 876-901, doi: 10.1111/gpr.1979.27.issue-4.

Kaufman, A., and G. Keller, 1983, Frequency and transient soundings: Elsevier.

Knight, J., and A. Raiche, 1982, Transient electromagnetic calculations using the Gaver-Stehfest inverse Laplace transform method: Geophysics, 47, 47-50, doi: 10.1190/1.1441280.

Lipton, I., 2008, Mineral resource estimate Solwara 1 project Bismarck Sea Papua New Guinea for Nautilus Minerals Inc: Technical Report Canadian, NI43-101 form $F 1$, http://www.nautilusminerals.com/i/pdf/2008-0201_Solwar1_43-101.pdf, accessed 29 February 2012.

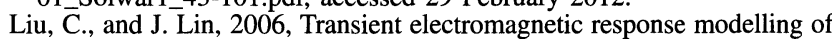
magnetic source on seafloor and the analysis of seawater effect: Chinese Journal of Geophysics, 49, 1726-1736.

Müller, H., T. Dobeneck, C. Hilgenfeldt, B. S. Felipo, D. Rey, and B. Rubio, 2012, Mapping the magnetic susceptibility and electric conductivity of marine surficial sediments by benthic EM profiling: Geophysics, 77, no. $1,1-14$, doi: $10.1190 /$ geo2010-0129.1.

Munkholm, M., and E. Auken, 1996, Electromagnetic noise contamination on transient electromagnetic soundings in culturally disturbed environments: Journal of Environmental Engineering Geophysics, 1, no. 2, 119-127, doi: 10.4133/JEEG1.2.119.

Nabighian, M., 1979, Quasi-static transient response of a conducting halfspace: An approximate representation: Geophysics, 44, 1700-1705, doi: 10.1190/1.1440931.

Palacky, G., and G. West, 1991, Airborne electromagnetic methods, in M. Nabighian, and E. Neitzel, eds., Electromagnetic methods in applied geophysics - Volume 2, Applications: SEG, 811-879.

Robb, L., 2005, Introduction to ore-forming processes: Blackwell Science.

Rona, P., 1984, Hydrothermal mineralization at seafloor spreading centres: Earth Science Reviews, 20, no. 1, 1-104, doi: 10.1016/0012-8252(94) 90080-1.

Schmidt, M., R. Botz, E. Faber, M. Schmitt, J. Poggenburg, D. GarbeSchönberg, and P. Stoffers, 2003, High-resolution methane profiles across anoxic brine-seawater boundaries in the Atlantis-II, Discovery, and Kebrit Deeps (Red Sea): Chemical Geology, 200, 359-375, doi: 10.1016/S00092541(03)00206-7.

Scholl, C., and R. Edwards, 2007, Marine downhole to seafloor dipoledipole electromagnetic methods and the resolution of resistive targets: Geophysics, 72, no. 2, WA39-WA49, doi: 10.1190/1.2434775.

Smith, R., R. Edwards, and G. Buselli, 1994, An automatic technique for presentation of coincident-loop, impulse-response, transient, electromagnetic data: Geophysics, 59, 1542-1550, doi: 10.1190/1.1443543.

Sørensen, K., and E. Auken, 2004, SkyTEM - A new high-resolution helicopter transient electromagnetic system: Exploration Geophysics, 35, 191-199, doi; 10.1071/EG04194.

Stehfest, H., 1970, Algorithm 368: Numerical inversion of Laplace transforms: Communications of the ACM, 13, no. 1, 47-49, doi: 10.1145/ 361953.361969.

von Herzen, R. J. Kirklin, and K. Becker, 1996, Geoelectric measurements at the TAG hydrothermal mound: Geophysical Research Letters, 23, 3451-3454, doi: 10.1029/96GL02077.

Vrbancich, J., P. Fullagar, and R. Smith, 2010, Testing the limits of AEM bathymetry with a floating TEM system: Geophysics, 75, no. 4, WA163WA177, doi: 10.1190/1.3463806.

Ward, S., and D. Hohmann, 1987, Electromagnetic theory for geophysical applications, in M. Nabighian, J. D. Corbett, and E. Neitzel, eds., Electromagnetic methods in applied geophysics - Volume 1, Theory: SEG, $131-311$.

Weidelt, P., 1984, Inversion transient-elektromagnetischer Messungen über geschichtetem untergund: Report 96720, BGR. 